\title{
Inter-model spread in the pattern effect and its contribution to climate sensitivity in CMIP5 and CMIP6 models
}

\author{
Yue Dong ${ }^{1}$, Kyle C. Armour ${ }^{1,2}$, Mark D. Zelinka ${ }^{3}$, Cristian Proistosescu ${ }^{4}$, David S. Battisti ${ }^{1}$, \\ Chen Zhou', Timothy Andrews' \\ ${ }^{I}$ Department of Atmospheric Sciences, University of Washington, Seattle, Washington \\ ${ }^{2}$ School of Oceanography, University of Washington, Seattle, Washington \\ ${ }^{3}$ Lawrence Livermore National Laboratory, Livermore, California \\ ${ }^{4}$ Joint Institute for the Study of the Atmosphere and the Ocean, University of Washington, \\ Seattle, Washington \\ ${ }^{5}$ Department of Atmospheric Physics, Nanjing University, Nanjing, China \\ ${ }^{6}$ Met Office Hadley Centre, Exeter, United Kingdom
}

Corresponding Author:

Yue Dong (dongy24@uw.edu)

\begin{abstract}
Radiative feedbacks depend on the spatial patterns of sea-surface temperature (SST) and thus can change over time as SST patterns evolve - the so-called 'pattern effect'. This study investigates inter-model differences in the magnitude of the pattern effect and how these differences contribute to the spread in the effective equilibrium climate sensitivity (ECS) within CMIP5 and CMIP6 models. Effective ECS from abrupt $4 \mathrm{xCO} 2$ simulations is on average $10 \%$ higher than that inferred from historical energy budget in CMIP5, this difference is reduced to 7\% on average in CMIP6, but still with a wide range across models. The (negative) net radiative feedback weakens over the course of the abrupt $4 \mathrm{xCO} 2$ simulations in the vast majority of CMIP5 and CMIP6 models, but this weakening is less dramatic on average in CMIP6. For both ensembles, the total variance in the effective ECS is found to be dominated by the spread in radiative response on fast timescales, rather than the spread in feedback evolution over time. Using Green's functions derived from two AGCMs shows that the spread in feedbacks on fast timescales may be primarily determined by atmospheric model physics, whereas the spread in feedback evolution towards longer timescales is primarily governed by evolving SST patterns. Inter-model spread in feedback evolution is well explained by differences in the relative warming in the West Pacific warm-pool regions for the CMIP5 models, but this relation fails to explain differences across the CMIP6 models, suggesting that stronger sensitivity of extratropical clouds to surface warming may also contribute to feedback changes in CMIP6 models.
\end{abstract}




\section{Introduction.}

Uncertainty in estimates of equilibrium climate sensitivity (ECS) - the equilibrium surface temperature change in response to a doubling of $\mathrm{CO}_{2}$ above pre-industrial levels - has long been linked to uncertainty in the radiative feedbacks $(\lambda)$, which govern the efficiency with which the climate system radiates energy to space per degree of surface warming. The strength of $\lambda$ is intrinsically set by black-body radiation, which is further modulated by radiative feedbacks associated with changes in atmospheric lapse rate, water vapor, surface albedo, and clouds. Among these, the cloud feedback has been found to be the primary source of ECS uncertainty (Webb et al. 2006; Soden and Held 2006; Dufresne and Bony 2008; Webb et al. 2013; Caldwell et al. 2016; Zelinka et al. 2016; Ceppi et al. 2017; Stevens et al. 2017; Caldwell et al. 2018; Zelinka et al. 2020). The low-cloud feedback is particularly uncertain (Bony and Dufresne 2005; Webb et al. 2006; Webb et al. 2015; Ceppi et al. 2017), leading to tremendous efforts in the community to constrain it (Bony et al. 2006).

Within global climate models (GCMs), ECS is often estimated based on a standard linear framework for global energy balance:

$$
\begin{gathered}
N=F+\lambda T, \\
\operatorname{ECS}=T_{\text {eq }}=-F_{2 \times} / \lambda_{\text {eq }},
\end{gathered}
$$

where $F$ is the effective radiative forcing (with $F_{2 x}$ representing forcing from $\mathrm{CO}_{2}$ doubling), and where the subscript $e q$ denotes the equilibrium state when $N$ approaches zero. All variables represent global-mean anomalies with respect to a pre-industrial state. A useful method to derive $\lambda$ and ECS from simulations of abrupt $\mathrm{CO}_{2}$ doubling or quadrupling is proposed by Gregory et al. 2004, by regressing net TOA radiation imbalance $(N)$ against surface-air-temperature change $(T)$ (hereafter referred to as 'Gregory $N$ - $T$ regression', with the graphical illustration of this regression referred to as a 'Gregory plot'). This method has been widely used to provide estimates of $\lambda$ (regression slope), $F_{2 \mathrm{x}}$ (from the y-axis intercept), and ECS (from the x-axis intercept), but is only valid under the assumption that $\lambda$ is constant over time, i.e., $\lambda=\lambda_{\text {eq }}$ at any given time. This general assumption may be violated for several reasons. For example, a discrepancy between $\lambda$ and $\lambda_{\text {eq }}$ may arise from nonlinear state-dependence of some feedbacks on global-mean or local temperature (e.g., Block and Mauritsen, 2013; Andrews et al. 2014; Bloch-Johnson et al. 2016). For instance, sea-ice albedo feedback will become less-positive as the amount of sea ice decreases with warming (Goosse et al. 2018) while the water vapor feedback (Meraner et al. 2013) or cloud feedback (Caballero and Huber 2013) may both become more positive with warming. Most importantly, the majority of GCMs in Coupled Model Intercomparison Project phases 5 and 6 (CMIP5 and CMIP6) exhibit a weakening of the negative net feedback as time evolves after $\mathrm{CO}_{2}$ forcing is imposed, shown as the curvature in the Gregory $N-T$ regression (Andrews et al. 2015; Armour 2017; Proistosescu and Huybers 2017; Lewis and Curry 2018). This time-dependence of $\lambda$ has been found to arise primarily from its dependence on the spatial pattern of sea-surface temperature (SST), which itself can evolve over time (Armour et al. 2013; Zhou et al. 2016; Haugstad et al. 2017; Ceppi and Gregory 2017; Andrews et al. 2018; Dong et al. 2019) - the so-called 'pattern effect' (Stevens et al. 2016). An important implication is that the climate sensitivity inferred from the historical energy budget is biased low compared to the climate sensitivity estimated over longer timescales under $\mathrm{CO}_{2}$ forcing due to the evolution of surface warming patterns (Armour 2017; Proistosescu and Huybers 2017; Andrews et al. 2018; Marvel et al. 2018; Dong et al. 2019; Gregory et al. 2019; Rugenstein et al. 2019). What is less-well understood, however, is what sets 
the magnitude of the pattern effect, as illustrated by the large inter-model spread in the degree of feedback curvature in the Gregory regression (Andrews et al. 2015; Armour 2017; Ceppi and Gregory 2017). Moreover, the contribution of model spread in feedback curvature to the model spread in ECS estimates has not yet been quantified. This work addresses these two key issues in both CMIP5 and CMIP6 models.

We first present an overview of net feedbacks in CMIP5 and CMIP6 models by showing the Gregory $N-T$ regression for the 150-yr-long simulations of abrupt $\mathrm{CO}_{2}$ quadrupling (hereafter abrupt4×CO2) (Fig. 1). Following Andrews et al. (2015), we calculate radiative feedbacks based on regression over a fast time-scale (years 1-20) and over a slow time-scale (years 21-150), noted hereafter as $\lambda_{1-20}$ and $\lambda_{21-150}$, respectively. We calculate values of $N$ and $T$ in each model with respect to their pre-industrial control simulations (piControl) after accounting for drift by subtracting the linear regression of piControl values over time segment corresponding to the abrupt $4 \times \mathrm{CO} 2$ simulation (following Forster et al. 2013 and Armour 2017). All of the anomalies used in this study are annual-mean quantities. Note that we use year 20 to separate the fast response on decadal timescales from the slow response on centennial timescales, following many existing studies, but results are insensitive to the year chosen (Andrews et al. 2015). ECS estimated using the regression method over the course of abrupt $4 \times \mathrm{CO} 2$ simulations is often referred to as the effective climate sensitivity (Andrews et al. 2015; Andrews and Webb 2017; Andrews et al. 2018; Gregory et al. 2019), as it presumably differs from the true ECS of the Earth system that would be found by equilibrating over multiple millennia (Rugenstein et al. 2019). In this study, we use several measures of the effective ECS derived from extrapolation of the Gregory $N-T$ regressions to the $\mathrm{x}$-axis (divided by two to account for $\mathrm{CO}_{2}$ quadrupling) and distinguish them with a subscript denoting the years over which the regression was performed. Specifically, we use ECS $\mathrm{EC}_{1-20}, \mathrm{ECS}_{21 \text { - }}$ 150 and $\mathrm{ECS}_{1-150}$, corresponding to values derived from the regressions over years 1-20, years 21150 , and years 1-150, respectively. Of these three, $\mathrm{ECS}_{21-150}$ provides the most accurate estimate of the true ECS in 8 GCMs analyzed by Rugenstein et al. (2019), so we will make this approximation and refer the effective ECS of each model to their $\mathrm{ECS}_{21-150}$ values here.

Fig. 1 shows that for both CMIP5 and CMIP6, the ensemble-mean (negative) net feedback weakens towards the longer timescales. That is, there is a positive change in the (negative) net feedback $\left(\Delta \lambda=\lambda_{21-150}-\lambda_{1-20}>0\right)$ across 23 of 24 CMIP5 models and 26 of 29 CMIP6 models, indicating that $\mathrm{ECS}_{1-20}$ is nearly always smaller than $\mathrm{ECS}_{21-150}$ in both CMIP5 and CMIP6. Comparing the two ensembles, we find that $\mathrm{ECS}_{1-20}$ and $\mathrm{ECS}_{21-150}$ on average are higher in CMIP6 relative to CMIP5, although they have larger variance in CMIP6 (Fig. 1; Tables 2, 3). Several upto-date studies of individual CMIP6 models (Gettelman et al. 2019 for CESM2, Golaz et al. 2019 for E3SM; Sellar et al. 2019 for UKESM1; Bodas-Salcedo et al. 2019 for HadGEM3; Andrews et al. 2019 for HadGEM3-GC3.1 and UKESM1) report that the higher values of ECS in their models are largely due to stronger positive cloud feedbacks, which is recently confirmed to be a common feature in the whole CMIP6 ensemble by Zelinka et al. (2020). Here, by quantifying $\lambda$ on different timescales, we find that both $\lambda_{1-20}$ (feedback strength on the fast timescale) and $\Delta \lambda$ (feedback change over time) are, on average, different in CMIP6 relative to CMIP5 (Fig. 1). Key questions are: (i) how do $\lambda_{1-20}$ and $\Delta \lambda$ contribute to the spread in ECS across models and between CMIP5 and CMIP6 ensembles, (ii) what causes the differences in $\Delta \lambda$ across models and between CMIP5 and CMIP6 ensembles, and (iii) what physical mechanisms govern $\lambda_{1-20}$ and $\Delta \lambda$ ? 


\section{Manuscript submitted to Journal of Climate (currently in revision) \\ ---- This is a non peer-reviewed version on EarthArXiv ----}

Motivated by the three questions, we assess the effective ECS, $\lambda_{1-20}$ and $\Delta \lambda$ within 24 CMIP5 models and 29 CMIP6 models (summarized in Table 1). In section 2, we investigate the source of model spread in the effective ECS relating the radiative response on fast timescale and the pattern effect on slow timescale, and also estimate the ECS bias relative to historical estimates in both ensembles. In section 3, we compare the ensemble-mean $\Delta \lambda$ in the CMIP5 and CMIP6 models. In section 4 , we investigate the inter-model spread in $\lambda_{1-20}$ and $\Delta \lambda$ separately, and track down the key regions of the pattern effect that are most responsible for driving the spread in $\Delta \lambda$ across the CMIP5 and CMIP6 models.

\section{The contribution of the pattern effect to the variance of ECS estimates.}

Fig. $1 \mathrm{~d}$ shows that $\Delta \lambda$ is on average smaller in CMIP6 models $\left(0.4 \mathrm{Wm}^{-2} \mathrm{~K}^{-1}\right)$ than in CMIP5 models $\left(0.53 \mathrm{Wm}^{-2} \mathrm{~K}^{-1}\right)$, despite the fact that $\mathrm{ECS}_{21-150}$ is on average higher in CMIP6 (Fig. 1f) (corresponding to an overall less-negative $\lambda$ ). That is, higher CMIP6-mean effective ECS is not coming from a stronger pattern effect (it is weaker, in fact), but presumbably from less-negative feedbacks on the fast timescale and stronger radiative forcing (Zelinka et al. 2020). However, there remains the possibility that inter-model spread in $\Delta \lambda$ may contribute to the spread in effective ECS. Therefore, we first estimate the degree to which $\Delta \lambda$ affects the spread in $\mathrm{ECS}_{21-150}$ across models (section $a$ ). Then we use abrupt $4 \times C O 2$ simulations as an analog for historical warming (following Lewis and Curry 2018) to estimate the degree to which the pattern effect causes historical estimates of effective ECS to be biased low relative to $\mathrm{ECS}_{21-150}\left(\right.$ or $\left.\mathrm{ECS}_{1-150}\right)$ in CMIP5 and CMIP6 models $(\operatorname{section} b)$.

\section{a. Correlation between $\mathrm{ECS}_{21-150}$ and $\mathrm{ECS}_{1-20}$}

Previous studies (Dufresne and Bony 2008; Caldwell et al. 2016) partitioning ECS into components associated with radiative feedbacks and radiative forcing have identified feedbacks as the dominant source of the ECS spread across models. To estimate the relative roles of $\lambda_{1-20}$ and $\Delta \lambda$ in setting ECS, we evaluate the correlation between $\mathrm{ECS}_{21-150}$ and $\mathrm{ECS}_{1-20}$. Without any pattern effect induced variance, $\mathrm{ECS}_{21-150}$ and $\mathrm{ECS}_{1-20}$ would be highly correlated.

The correlation $\left(r^{2}\right)$ between $\mathrm{ECS}_{21-150}$ and $\mathrm{ECS}_{1-20}$ is 0.69 in CMIP5 and 0.70 in CMIP6, respectively; both correlations are statistically significant at $95 \%$ confidence level. This indicates that the total variance of $\mathrm{ECS}_{21-150}$ can be primarily explained by the spread in the radiative response on fast timescales, even without considering the feedback evolution due to the pattern effect. The degree to which feedbacks change over time $(\Delta \lambda)$ thus explains, at most, $30 \%$ of the total variance in ECS in both model ensembles, given the fact that $\lambda_{1-20}$ and $\Delta \lambda$ are weakly correlated $\left(r^{2}=0.3\right.$ for CMIP5 and $r^{2}=0.2$ for CMIP6).

These results suggest that the differences in feedback evolution on longer timescales contribute much less to the spread in $\mathrm{ECS}_{21-150}$ than do the differences in feedbacks on the fast timescales, even though this measure of ECS here is based on the latter period of the abrupt $4 x \mathrm{CO} 2$ simulations (years 21-150). However, it is worth noting that in both ensemble-means and individual models,

$\Delta \lambda$ is generally positive (23 of 24 CMIP5 models and 26 of 29 CMIP6 models), therefore the $\mathrm{ECS}_{21-150}$ is nearly always greater than that derived from early portion of the simulation $\left(\mathrm{ECS}_{1-20}\right)$. 
Thus, while $\lambda_{1-20}$ is the major driver of variance in ECS, ignoring $\Delta \lambda$ and using an assumption of time-invariant feedbacks would lead to a low bias in the estimates of the true ECS (as estimated here by $\mathrm{ECS}_{21-150) \text {. }}$

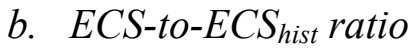

As many studies have revealed, the value of ECS estimated from historical energy budget constraints is biased low based on the behavior of fully-coupled and atmosphere-only GCM simulations (Armour 2017; Proistosescu and Huybers 2017; Andrews et al. 2018; Lewis and Curry 2018; Marvel et al. 2018; Gregory et al. 2019). Multiple factors have contributed to the spatial pattern of warming, and thus the pattern effect, over the historical period, including the inherent timescales of ocean adjustment to radiative forcings (e.g. Marvel et al. 2016; Armour 2017; Proistosescu and Huybers 2017) as well as unforced internal climate variability (e.g., Andrews et al. 2018; Marvel et al. 2018). The distinction between forced and unforced pattern effects is further discussed in Dessler et al. (2020). In this section, we consider how the forced pattern effect may bias values of ECS inferred from historical warming based on the behavior of the CMIP5 and CMIP6 models' response to $\mathrm{CO}_{2}$ forcing.

Following Armour (2017) and Andrews et al. (2018), we rewrite Eq. (2) as

$$
\mathrm{ECS}=-\frac{F_{2 \times}}{\lambda_{\text {eq }}}=-\frac{F_{2 \times}}{\lambda_{\text {hist }}+\lambda^{\prime}} \text {. }
$$

where $\lambda_{\text {hist }}$ is the feedback parameter estimated from historical energy budget constraints, $\lambda^{\prime}$ is the change in feedback at the equilibrium state relative to the historical period. Using $\lambda_{\text {hist }}$ based on historical observations, one can make an estimate of climate sensitivity (termed ECS $\mathrm{S}_{\text {hist }}$ herein):

$$
\mathrm{ECS}_{\text {hist }}=-\frac{F_{2 x}}{\lambda_{\text {hist }}},
$$

which will underestimate the value of ECS if $\lambda^{\prime}>0$. Note that while $\lambda^{\prime}$ is expected to have the same sign of $\Delta \lambda$ (positive in most GCMs), their magnitudes will be different. $\Delta \lambda$ is defined as the change in feedbacks between the first 20 years and the last 130 years of abrupt $4 x C O 2$ simulations, whereas $\lambda^{\prime}$ is defined in terms of how feedbacks will change from historical warming to equilibrium warming under $\mathrm{CO}_{2}$ forcing.

Armour (2017) (hereafter A17) and Lewis and Curry (2018) (hereafter LC18) proposed a ratio of ECS to ECS hist $_{\text {(hereafter "ECS-to-ECS }}$ hist ratio") to quantify the bias in ECS estimates,

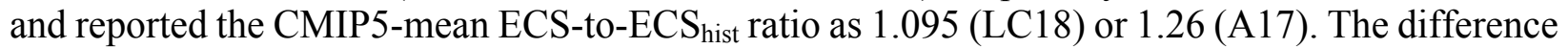
between their estimates is attributed to the differences in the method and timescale of regression used and differences in assumptions about how $\mathrm{CO}_{2}$ forcing scales with $\mathrm{CO}_{2}$ concentration (LC18).

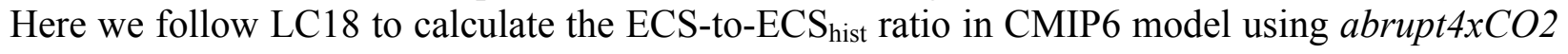
experiments. Specifically, we obtain ECS $_{\text {hist }}$ by regressing $N$ against $T$ over years 2-50 of each model's abrupt $4 x \mathrm{CO} 2$ simulation, which is shown to be an effective analog for historical warming by LC18. We also calculate $F_{2 \mathrm{x}}$ by scaling the y-axis intercept of the regression of $N$ against $T$ over years 2-10. ECS here is estimated from the regression of $N$ against $T$ over years 21-150 (equal to $\mathrm{ECS}_{21-150}$ ), which is the same period used in both A17 and LC18, but using Deming regression to be consistent with LC18. For comparison, we also provide the results using a more conventional estimate of ECS derived from the $N$-T regression over years $1-150\left(\mathrm{ECS}_{21-150}\right.$; shown in parenthesis in Table 4). 


\section{Manuscript submitted to Journal of Climate (currently in revision) ---- This is a non peer-reviewed version on EarthArXiv ----}

The results of individual CMIP6 models and ensemble-means are shown in Table 4. The pattern-effect induced feedback evolution from the historical period to equilibrium $\left(\lambda^{\prime}\right)$ is on average weaker in CMIP6 $\left(0.06 \mathrm{Wm}^{-2} \mathrm{~K}^{-1}\right)$ relative to CMIP5 $\left(0.092 \mathrm{Wm}^{-2} \mathrm{~K}^{-1}\right)$, so that the model

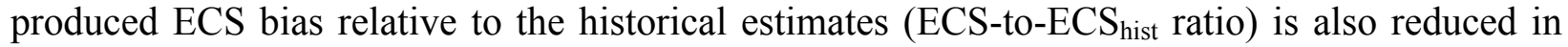
CMIP6 ensemble-mean (6\%) compared to CMIP5 ensemble-mean (9.5\%; consistent with LC18). This suggests that the latest generation of GCMs produce an overall smaller ECS-to-ECS hist $_{\text {ratio, }}$ consistent with results above that the pattern effect is slightly smaller in the abrupt $4 x \mathrm{CO} 2$ simulations. However, there remains a large spread across CMIP6 models: $\lambda^{\prime}$ varies from $0.3 \mathrm{Wm}^{-}$ ${ }^{2} \mathrm{~K}^{-1}$ to $-0.23 \mathrm{Wm}^{-2} \mathrm{~K}^{-1}$, corresponding to ECS values that are $40 \%$ higher to $12 \%$ lower than $\mathrm{ECS}_{\text {hist. }}$.

We note an important caveat of this analysis regarding the calculation of $\mathrm{ECS}_{\text {hist. }}$ There are several ways to estimate $\mathrm{ECS}_{\text {hist }}$ from GCM simulations. Using abrupt4xCO2 simulations (e.g.

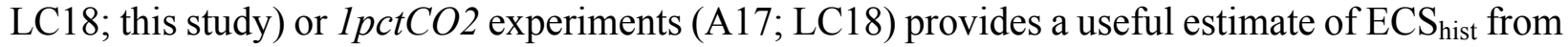
historical coupled runs, but is not a perfect analog. Several recent studies instead use coupled historical simulations, where all historical radiative forcing agents and an unforced pattern effect are included (Marvel et al. 2016: Gregory et al. 2019; Andrews et al. 2019). In general, including realistic time-evolution of both $\mathrm{CO}_{2}$ and non- $\mathrm{CO}_{2}$ forcings may produce different values of $\mathrm{ECS}_{\text {hist }}$ than that estimated from idealized abrupt4xCO2 simulations. For example, Andrews et al. (2019) found that ECS $\mathrm{S}_{\text {hist }}$ within historical simulations of HadGEM3-GC3.1-LL is 4.7K, with a ECS-toECS $_{\text {hist }}$ ratio of 1.21. For comparison, using HadGEM3-GC3.1-LL's abrupt4xCO2 simulation, our

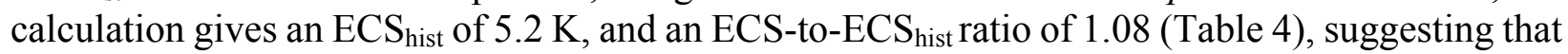
the values reported here may underestimate the historical pattern effect. However, as our main focus is to compare CMIP5 and CMIP6 ensembles rather than providing the most accurate estimates for each model, this analysis provides valuable information on the difference in pattern effect between the two ensembles. Future work employing simulations of Radiative Forcing Model Intercomparion Project (RFMIP; Pincus et al. 2016) to accurately quantify radiative feedbacks in the historical simulations of CMIP6 models is needed to shed light on this in greater detail.

\section{The consistency and difference in ensemble-mean $\Delta \lambda$ between CMIP5 and CMIP6}

Even though $\Delta \lambda$ does not contribute as much as $\lambda_{1-20}$ to the inter-model spread in ECS, it substantially affects ECS estimates for both CMIP5-mean and CMIP6-mean projections (comparing $\mathrm{ECS}_{1-20}$ to $\mathrm{ECS}_{21-150}$ in Fig.1 e, f). In this section, we first compare the global-mean $\Delta \lambda$ and its individual components partitioned by radiative kernels. We then show the spatial patterns of ensemble-mean local $\Delta \lambda$ from CMIP5 and CMIP6 models. We also provide a comparison of SST patterns to aid in uncovering the causes of ensemble differences.

Fig. 2 shows global-mean net $\Delta \lambda$ and its individual components associated with changes in atmospheric temperature, water vapor, lapse rate, surface albedo and clouds, estimated using radiative kernels (Huang et al. 2017) as described in Zelinka et al. (2020). We calculate the cloud feedback using radiative kernels by removing cloud masking effects from the temperaturemediated change in net cloud radiative effect. An overall consistency between CMIP5 and CMIP6 is found in the fact that the dominant contribution to the ensemble-mean $\Delta \lambda$ comes from the net cloud component $\left(\Delta \lambda_{\mathrm{CLD}}\right)$, followed by the sum of lapse rate $\left(\Delta \lambda_{\mathrm{LR}}\right)$ and water vapor $\left(\Delta \lambda_{\mathrm{WV}}\right)$ components. Both CMIP5 and CMIP6 have a large spread in the net $\Delta \lambda$, primarily owing to the 


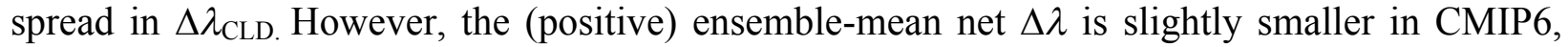
primarily due to a smaller surface-albedo feedback change $\left(\Delta \lambda_{\mathrm{ALB}}\right)$, particularly from the Northern Hemisphere $(\mathrm{NH})$.

We next show the spatial patterns of ensemble-mean local feedbacks for the CMIP5 and CMIP6 models (Figs 3, 4). The feedback patterns are first calculated for each model by regressing the corresponding local $N$ against global-mean $T$ over the two separate time periods, and then averaging across models. The patterns of local contributions to the net feedback change are qualitatively consistent between the two ensemble-means (Figs 3, 4, the first row). That is, the positive changes in the net feedback primarily come from the tropical eastern Pacific. This is a region where cool SSTs and a strong capping inversion promote ubiquitous low clouds in the climatology. Because warmer surface temperatures and weaker low-level stability in this region both reduce low cloud cover, delayed warming in this region will yield a less-negative feedback during the approach toward equilibrium (Zhou et al. 2016; Ceppi and Gregory 2017). Indeed, among all individual components, cloud feedback and lapse-rate feedback contribute the most to the positive change in the net feedback over this region in both CMIP5 and CMIP6. The major difference between the two ensembles lies in the Arctic (Fig. 4b), where positive surface-albedo feedback strengthens with time in the CMIP5 models (Fig. 3 bottom row) but weakens over time in the CMIP6 models (Fig. 4a bottom row), consistent with the regional attribution results in Fig. 2.

The difference in the surface-albedo feedback, which arises from local sea-ice and/or snow melting, is closely associated with the difference in local temperature changes. We show the SST warming patterns on the fast and slow timescales for CMIP5 and CMIP6 in Fig. 5 (computed as regression slope of local SST change against global-mean SST change). In CMIP6, the relative warming in the Arctic over the first 20 years is stronger than that in CMIP5 (Fig. 5c), but becomes weaker over the following decades (Fig. 5f). That is, the CMIP6 multi-model mean exhibits a stronger inter-hemispheric asymmetry in the warming pattern (Fig. 5i), which features rapid warming in the Arctic and NH midlatitudes on fast timescales and delayed warming in the Southern Ocean and southern eastern Pacific on longer timescales (Fig. 5h). As a result, although the (positive) surface-albedo feedback strengthens with time over the Southern Ocean leading to a positive $\Delta \lambda_{\mathrm{ALB}}$ in both CMIP5 and CMIP6 (Figs, $2,3,4$ ), the change in the Arctic warming rate yields a weakening of surface-albedo feedback (i.e. negative $\Delta \lambda_{\mathrm{ALB}}$ ) within CMIP6 models (Fig. 2 , Fig. 4 a bottom row). This negative $\Delta \lambda_{\mathrm{ALB}}$ thus compensates the global-mean $\Delta \lambda_{\mathrm{ALB}}$ (Fig. 2 ), causing an overall smaller $\Delta \lambda$ in CMIP6 models.

\section{The source of the inter-model spread in $\Delta \lambda$ across CMIP5 and CMIP6}

We next move away from the multi-model mean perspective, to consider why individual models have different values of $\Delta \lambda$. We find it conceptually helpful to consider that radiative feedbacks and their changes may be influenced by both atmospheric model physics and SST patterns. To separate the two factors, we make use of radiative feedback 'Green's functions' (Zhou et al. 2017; Dong et al. 2019), which will be introduced in section $a$. In section $b$ and section $c$, we investigate the major source of the inter-model spread in $\Delta \lambda$ across the CMIP5 and CMIP6 models, respectively. 


\section{Manuscript submitted to Journal of Climate (currently in revision)

\section{a. Green's functions}

To separate the effect of SST patterns and the effect of model physics, we use radiative feedback Green's functions, as they predict the radiative response based solely on SST anomaly patterns, given the atmospheric physics of the parent model from which they were derived. The basis of a Green's function is a Jacobian matrix, representing the sensitivity of any regional response to regional SST anomalies, which consists of both local and nonlocal effects of changes in SST. The full Jacobian is calculated from a series of prescribed-SST simulations within an AGCM, each with a single patch of SST anomalies on the top of climatological SSTs. Then, convolving the Jacobian with a global SST anomaly pattern can predict the global response to the given SST pattern, based on the assumption of spatial linearity, which has been shown to be a good approximation (Zhou et al. 2017; Dong et al. 2019). Hence, applying the Green's functions linearly separates the differences in SST patterns and the differences in the sensitivity of radiative feedbacks on SST patterns.

Here we employ two Green's functions: one derived from the Community Atmosphere Model version 5 (CAM5) by Zhou et al. (2017), and one derived from CAM4 by Dong et al. (2019). The major difference between CAM4 and CAM5 Green's functions lies in the representation of cloud properties within the two models, which are reported to be more realistic in CAM5 (Kay et al. 2012), although both models exhibit large biases in the subtropical marine boundary layer cloud regimes. Throughout this study, we use their 2-dimensional global-mean Jacobians (denoted as $\mathcal{J}_{X}$, the sensitivity of a global-mean response $X$ to each grid of SST anomalies), for computational efficiency as our focus is on global-mean quantities. To compute feedback parameters from the Green's functions, we first reconstruct annual global-mean net TOA radiative response $(R)$ and surface air temperature response $(T)$ by convolving the Green's functions $\mathcal{J}_{X}$ with each model's annual-mean global SST anomalies $(\operatorname{SST}(\boldsymbol{r}))$,

$$
X=\mathcal{J}_{X} \cdot \operatorname{SST}(\boldsymbol{r}),
$$

where $X$ can be any response (e.g. $R, T$ ), $\boldsymbol{r}$ denotes global pattern of SST anomalies. Then $\lambda_{1}, \lambda_{2}$, and $\Delta \lambda$ are calculated following the same regressions used to process model outputs. Note that the Green's function can only predict TOA radiative response $R(=\lambda T)$, which is different to the net TOA radiation imbalance $(N)$ in fully-coupled GCMs, because the latter includes the effective radiative forcing of $\mathrm{CO}_{2}$ quadrupling $F_{4 \times}: N=F_{4 \times}+R$. Indeed, the effective radiative forcing also varies slightly across models; but it is abruptly imposed and held constant over time. Therefore, while radiative forcing matters for ECS itself, its absence does not cause any inconsistency in the estimates of feedbacks (defined as the regression slope in Gregory plots) between Green's functions and the GCM simulations.

\section{b. Inter-model spread in $\Delta \lambda$ across CMIP5 models}

We first show the comparison of feedbacks from CMIP5 GCMs and those reconstructed by the CAM4/CAM5 Green's functions (Fig. 6). Both Green's functions poorly capture $\lambda_{1-20}$ but approximately reproduce GCM values of $\Delta \lambda$, suggesting that $\lambda_{1-20}$ and $\Delta \lambda$ are governed by different processes. The failure of the Green's functions in reconstructing $\lambda_{1-20}$ may come from several factors, for example, the Green's functions fail to account for the radiative response to land warming which emerges generally on fast timescales. However, we favor the interpretation that the spread in $\lambda_{1-20}$ is primarily determined by each model's atmospheric physics (e.g., cloud 


\section{Manuscript submitted to Journal of Climate (currently in revision) ---- This is a non peer-reviewed version on EarthArXiv ----}

parameterizations). Therefore, the radiative responses from each model cannot be captured by Green's functions derived from either CAM4 or CAM5, which have distinct atmospheric physics. On the other hand, the fact that both Green's functions more accurately reproduce $\Delta \lambda$, even though they are built from different models, suggests that the spread in $\Delta \lambda$ arises primarily from the changes in SST patterns and is largely insensitive to model physics.

We next investigate what regions of SSTs drive the inter-model spread in $\Delta \lambda$ across the CMIP5 models. Previous studies have pointed out the importance of tropical warming through changing cloud and lapse-rate feedbacks. Zhou et al. (2016) proposed the role of the tropical eastern Pacific, where relative cooling in recent decades is thought to be responsible for driving an increase in local low cloud and a more-negative cloud feedback. Andrews and Webb (2017) further established a mechanism associated with east-west tropical Pacific SST gradient that governs the change in tropospheric stability, and therefore the change in low clouds and lapse rate. Silvers et al. (2018) highlighted changes in low clouds throughout the tropics beyond the traditional stratocumulus regimes in driving decadal variability of feedbacks over the historical period. Recently, Dong et al. (2019) proposed that $\Delta \lambda$ tracks the ratio of warming in the West Pacific warm-pool (WP) regions relative to warming in the rest of global ocean areas $(\gamma)$. Here we test this mechanism by examining the correlation of $\Delta \lambda$ against the proposed WP warming ratio change $(\Delta \gamma)$ across models.

To calculate $\Delta \gamma$ for all CMIP5 and CMIP6 models, we define WP regions in this study as grid cells within $30^{\circ} \mathrm{S}-30^{\circ} \mathrm{N}, 30^{\circ} \mathrm{E}-160^{\circ} \mathrm{W}$ that have an upward vertical velocity at $500 \mathrm{hPa}\left(\omega_{500}\right)$ in the piControl simulation. Unlike the fixed rectangular area in the west Pacific used in Dong et al. (2019), this updated metric takes into account mean-state biases, ensuring that in each model the WP regions capture the radiative responses in regions of deep convection. Note that results using the fixed region in Dong et al. (2019) are similar to those shown here. We also simplify $\gamma$ to be the WP SST warming relative to global-mean surface air temperature changes, calculated as the regression slope of the averaged $S S T$ over the selected WP regions against global-mean $T$, over the two time periods used throughout this study (years 1-20 for $\gamma_{1-20}$, years 21-150 for $\gamma_{21-150}$, and $\Delta \gamma$ $\left.=\gamma_{21-150}-\gamma_{1-20}\right)$.

Fig. 7a shows that $\Delta \lambda$ is well correlated with $\Delta \gamma$ for CMIP5 models (with $r^{2}=0.63$ ). Although many approximations are made in the derivation (Dong et al. 2019), the simple metric $\Delta \gamma$, which includes no information about radiative response, explains over $60 \%$ of the variance in CMIP5 $\Delta \lambda$. The physical mechanism, as discussed in Dong et al. (2019), is the preeminent impact of WP warming on global TOA radiation change via deep convection. Over the WP regions, where the surface is tightly coupled to the free troposphere by deep convection, surface warming directly enhances upper tropospheric warming. This leads to a stronger negative lapse-rate feedback and a more-negative cloud feedback over low-cloud regions caused by increased lower tropospheric stability, which together promotes a more efficient radiative damping at TOA. On the other hand, the weaker coupling between surface and upper troposphere in all other regions results in a weak TOA radiation response to surface warming. This leads to a weaker negative lapse-rate feedback, and a more-positive low-cloud feedback, hence, resulting in an inefficient radiative damping (see Dong et al. 2019, Figs. 4, 5). The key importance of warm pool warming for TOA radiation 
changes is also supported by observational evidence (Zhou et al. 2016; Ceppi and Gregory 2017; Fueglistaler 2019).

To further demonstrate the proposed mechanism, we select three representative models that have large positive $\Delta \lambda$ (GISS-E2-R), small positive $\Delta \lambda$ (IPSL-CM5B-LR), and small negative $\Delta \lambda$ (CNRM-CM5), respectively. $\Delta \lambda$ is demonstrated as the degree of nonlinearity in the Gregory plots for each model (Figs $8 \mathrm{a}-\mathrm{c}$ ). We then show their SST warming patterns defined as local SST changes regressed against global-mean SST changes, denoted by $S S T^{*}$ (Figs $8 \mathrm{~d}-1$ ). In this context, any grids with values above 1 (in red) have local warming exceeding global-mean warming in the given period, and those with values below 1 (in blue) have local warming weaker than globalmean warming. In GISS-E2-R, the warm-pool regions warm up relatively quickly during the first 20 years, but no longer keep pace with other oceans (e.g. the Southern Ocean) over the last 130 years. This sharp transition of surface warming from tropical ascent regions to all other regions is responsible for the large $\Delta \lambda$. In IPSL-CM5B-LR, the WP regions do not warm substantially faster than global warming on the fast timescale, so that the change in the relative warming over WP regions is weaker, leading to a smaller $\Delta \lambda$. In CNRM-CM5, the WP regions warm relatively faster on the longer timescales, leading to a nearly zero change in WP regions in contrast to the other two models, and driving $\Delta \lambda$ of an opposite sign. This comparison shows that the CMIP5 values of $\Delta \lambda$ can be well characterized by the ratio of warm-pool to global-mean warming, suggesting an important role of tropical convective regions in modulating the strength of radiative feedbacks in CMIP5.

\section{c. Inter-model spread in $\Delta \lambda$ across CMIP6 models}

For CMIP6 models, we first repeat the analysis applying the WP warming ratio. Interestingly, the above theory does not seem to hold as well for CMIP6 models (Fig. 7b), suggesting that the $\Delta \lambda$ spread in the latest models may not directly trace to relative warm-pool warming. One may ask whether this is because the deep convection in other regions (e.g. Atlantic Ocean warm-pool regions) carry more weight in the CMIP6 ensemble. To identify where is the key region for driving feedback changes, we regress global-mean $\Delta \lambda$ onto local $\Delta S S T^{*}$ (the change in the relative warming rate from fast timescale to slow timescale) across CMIP5 and CMIP6 models, respectively, and evaluate the local correlation coefficient $(r)$. Note that $S S T^{*}$ is calculated as the local SST change relative to global-mean SST change, and $\Delta$ is defined as the late period (years 21-150) minus the early period (years 1-20).

The resulting correlation maps $(r)$ are shown in Fig. 9. The positive correlation indicates that models that have stronger positive global-mean $\Delta \lambda$ tend to show a locally delayed warming as approaching to equilibrium, whereas the negative correlation indicates that models that have stronger positive global-mean $\Delta \lambda$ tend to show a local warming predominately on the fast timescale. The magnitude of correlation efficient illustrates the degree to which the inter-model spread in $\Delta \lambda$ correlates with the differences in local warming rates. For example, Fig. 9a shows a strong negative correlation over Indo-Pacific deep convective regions. It supports the idea that the CMIP5 values of $\Delta \lambda$ is primarily governed by the difference in the relative warming in the West Pacific warmpool regions, where stronger warming on the fast timescale gives rise to a stronger positive $\Delta \lambda$. This is achieved mostly through $\Delta \lambda_{\mathrm{CLD}}$ (Fig. 9c) and $\Delta \lambda_{\mathrm{LR}}$ (Fig. 9g). However, the result of CMIP6 
highlights equatorial eastern Pacific and SH midlatitudes in addition to tropical Indian ocean (Fig. 9b), which are mostly reflected in the pattern of $\Delta \lambda_{\text {CLD }}$ (Fig. 9d). This comparison suggests that the CMIP5 values of $\Delta \lambda$ may be primarily dominated by surface warming in the broad tropical convective regions, whereas the CMIP6 values of $\Delta \lambda$ may be influenced more by surface warming in the tropical subsidence regions and extratropics.

Although it is also possible that the correlation between East Pacific warming and $\Delta \lambda$ is not causal but comes about through correlations between East Pacific and SH extratropical warming rates (Fig. 9b), we discuss possible reasons focusing on the cloud response to SH extratropical warming as highlighted in Fig. 9d. In addition to the results shown in Fig. 7 (b), we also found that both Green's functions fail to reproduce CMIP6 $\Delta \lambda$ (not shown), even though they capture $\Delta \lambda$ in CMIP5 models (Figs. 6c, d). One possible reason is the changes associated with extratropical clouds in CMIP6 models, whose feedbacks have strengthened in CMIP6 owing to changes in their sensitivities to local environmental conditions which may be tied to changes in their mean-state properties (Zelinka et al 2020). These changes may give rise to a different dependence of cloud feedbacks on SST pattern, presumably with stronger cloud radiative response to Southern Ocean warming. In this case, the global TOA radiation change may not be dominated by the tropical warm-pool warming as seen in CAM4 Green's function for example (see Dong et al. 2019 Fig. 11), but will be substantially influenced by the Southern Ocean warming as well. That is, the delayed Southern Ocean warming would result in a stronger pattern effect on the cloud feedback. If this is the case, new Green's functions with up-to-date GCMs may be helpful in shedding light on this issue, as the CAM4 and CAM5 Green's functions may be systematically different from those derived from CMIP6 models.

Another possible reason is the nonlinear state-dependence of extratropical cloud feedback, particularly the mixed-phase cloud feedback associated with cloud phase change. This negative feedback arises from the brightening of the clouds as they become increasingly composed of liquid droplets with warming. Therefore, it depends on the mean-state of ice/liquid fraction of the clouds, with more ice in the initial state leading to a stronger negative-feedback with warming (Tsushima et al. 2006; Storelvmo et al. 2015; McCoy et al 2015). Many CMIP6 models now have higher climatological cloud liquid water fractions, in better agreement with observations (Bodas-Salcedo et al. 2019; Gettelman et al. 2019; Zelinka et al. 2020). Bjordal et al. (in revision) shows that in CESM2, with the inclusion of a new mixed-phase ice nucleation scheme, the negative mixed-phase cloud feedback weakens with warming from the first 20 years to the last 20 years of abrupt4xCO2 simulation, particularly over the Southern Ocean, as the amount of ice decreases allowing for no further phase change to happen (see their Fig. 3). This weakening towards longer timescales in their simulations leads to a positive $\Delta \lambda_{\text {CLD }}$ over the Southern Ocean, which is primarily driven by the nonlinear state-dependence rather than by the pattern effect. If this case holds more generally across the CMIP6 models, the nonlinear state-dependence of $\Delta \lambda_{\text {CLD }}$ on the Southern Ocean warming may never be captured by any Green's functions, as the method relies on linear estimation.

In summary, we found the CMIP5 and CMIP6 ensembles on average highlight different regions where surface warming can largely influence the magnitude of global-mean $\Delta \lambda$ (Fig. 9). In CMIP5, inter-model differences in $\Delta \lambda$ are overall driven by inter-model differences in the surface warming rates over the West Pacific warm-pool region, where surface warming has strong remote impact on global TOA radiation changes (Dong et al. 2019). In CMIP6, inter-model differences in $\Delta \lambda$ 


\section{Manuscript submitted to Journal of Climate (currently in revision) ---- This is a non peer-reviewed version on EarthArXiv ----}

(and the cloud component $\Delta \lambda_{\mathrm{CLD}}$ in particular) appear to have more contributions from extratropical warming in addition to tropical warming. Specific physical mechanisms are under investigation. Here we speculate that the stronger sensitivity of feedbacks on the delayed extratropical warming may result either from the stronger pattern effect (stronger cloud radiative response to surface warming in this region), or from the nonlinear state-dependence of extratropical cloud feedback on the mean-state of the liquid fraction in the clouds.

\section{Conclusions}

In this study, we investigated the changes in radiative feedbacks over time and their contributions to climate sensitivity from abrupt $4 \times C O 2$ simulations within 24 CMIP5 GCMs and 29 CMIP6 models. Comprehensive comparisons were made between the two CMIP generations and between individual models. To examine the time-variation of feedbacks, we derived feedback parameters from the Gregory regressions between the net TOA radiation imbalance and surface air temperature change over years $1-20$ as $\lambda_{1-20}$ and years $21-150$ as $\lambda_{21-150}$, and use $\Delta \lambda\left(=\lambda_{21-150}-\right.$ $\left.\lambda_{1-20}\right)$ to represent the feedback changes over time.

We found that on average the effective ECS derived from the regression is higher and $\Delta \lambda$ is smaller in CMIP6 relative to CMIP5. We then evaluated the correlation between $\mathrm{ECS}_{21-150}$ (derived from years 21-150; featuring long-term response) and $\mathrm{ECS}_{1-20}$ (derived from years 1-20; featuring fast response governed primarily by $\left.\lambda_{1-20}\right)$. The correlation $\left(r^{2}\right)$ is 0.69 for CMIP5 and 0.70 for CMIP6, suggesting that the variance in ECS (as estimated by $\mathrm{ECS}_{21-150}$ ) is dominated by the differences in radiative response on the fast timescale, rather than the differences in $\Delta \lambda$. This also explains the fact that a greater $\Delta \lambda$ generally leads to a greater ECS within individual climate models, yet the higher ECS in the CMIP6 models occurs despite smaller $\Delta \lambda$. We also compared the ECSto-ECS $\mathrm{E}_{\text {hist }}$ ratio, representing the model-produced ECS bias relative to historical estimates, between CMIP5 and CMIP6. We found the feedback difference between the historical period and the equilibrium under $\mathrm{CO}_{2}$ forcing is on average smaller in CMIP6, and the CMIP6-mean ECS-toECS $_{\text {hist }}$ ratio is also slightly reduced, on average, relative to CMIP5, suggesting a weaker forced pattern effect in CMIP6 abrupt4xCO2 simulations. We note that although differences between two ensemble means are discussed in this study, there remains a large spread in feedback time-variation and ECS estimates across both CMIP5 and CMIP6 models.

Although the spread in $\Delta \lambda$ contributes less to the spread in ECS than does atmospheric model physics, understanding the magnitude of $\Delta \lambda$ and the pattern effect is still of a great importance to constrain ECS on longer timescales. By comparing the multi-model mean $\Delta \lambda$ in the CMIP5 and CMIP6 models, we see great similarities in the spatial patterns of $\Delta \lambda$, highlighting the cold tongue regions with delayed warming. An overall smaller ensemble-mean $\Delta \lambda$ in the CMIP6 models is primarily due to the difference in surface-albedo feedback over the Arctic. While the positive surface-albedo feedback generally strengthens with time in CMIP5, it weakens over time in CMIP6, compensating the global-mean change in surface-albedo feedback. But we caution that the differences between the ensemble-mean $\Delta \lambda$ are not statistically significant given the large spread across models, and the results may be subject to change as more models come in. 


\section{Manuscript submitted to Journal of Climate (currently in revision) ---- This is a non peer-reviewed version on EarthArXiv ----}

Because both model physics and surface warming patterns are important for driving $\Delta \lambda$, we employ Green's functions to isolate their contributions and investigate why individual models produce different $\Delta \lambda$. The Green's functions used in this study are derived from two GCMs, which intrinsically represent the given model physics of CAM4 or CAM5 but can be independently applied to different SST anomaly patterns. When applied to the CMIP5 models, the Green's functions reproduce $\Delta \lambda$ well but cannot capture $\lambda_{1-20}$, suggesting that $\Delta \lambda$ is primarily set by the differences in warming patterns, while $\lambda_{1-20}$ is presumably determined by the differences in model physics. Building upon Dong et al. (2019), the spread in $\Delta \lambda$ is found to be well correlated with the change in the warm-pool warming ratio, defined as the relative ocean warming from warm-pool ascent regions to global-mean surface air warming. Across CMIP5 models, this simple metric is able to explain over $60 \%$ variance of $\Delta \lambda$. Models showing greater $\Delta \lambda$ generally have West Pacific warm-pool regions warming up more quickly than the rest of world oceans on the fast timescale, but more slowly on longer timescales. This transition, on the other hand, is less significant in models that produce smaller $\Delta \lambda$. Regression of global-mean $\Delta \lambda$ against local warming rates also highlights the West Pacific warm-pool regions as the dominant control driving $\Delta \lambda$ variance across CMIP5 models, consistent with recent observations identifying the warm-pool as a key region controlling global radiation (e.g., Fueglistaler 2019).

However, the regression analysis across CMIP6 models show a different spatial distribution, with extratropics being highlighted in addition to tropics, suggesting that the CMIP6 values of $\Delta \lambda$ may not be dominated by tropical warming. The specific mechanism needs to be further uncovered; we speculate here that it may be partly attributable to a stronger sensitivity of extratropical clouds to surface warming. Future studies employing Green's function approach built from the CMIP6 models may bring more insights on investigating the pattern effect within the latest generation of GCMs, but will have limitations in the case that nonlinear state-dependence of feedbacks also contributes to the changes in feedbacks with time.

\section{Acknowledgements}

We thank Stephen A. Klein and Masahiro Watanabe for insightful discussions. We acknowledge the World Climate Research Programme, which, through its Working Group on Coupled Modelling, coordinated and promoted CMIP6. We thank the climate modeling groups for producing and making available their model output, the Earth System Grid Federation (ESGF) for archiving the data and providing access, and the multiple funding agencies who support CMIP6 and ESGF. YD, KCA and CP were supported by National Science Foundation Grant AGS1752796. MDZ's work was supported by DOE's Regional and Global Model Analysis Program and was performed under the auspices of the U.S. Department of Energy under Contract DEAC52-07NA27344. DSB was supported by the Tamaki Foundation. CZ was supported by NSFC 41875095. TA was supported by the Met Office Hadley Centre Climate Programme funded by Department for Business, Energy and Industrial Strategy (BEIS) and Department for Environment, Food and Rural Affairs (Defra). 


\section{Manuscript submitted to Journal of Climate (currently in revision) ---- This is a non peer-reviewed version on EarthArXiv ----}

\section{References}

Andrews, T., Gregory, J. M., Webb, M. J., \& Taylor, K. E. (2012). Forcing, feedbacks and climate sensitivity in CMIP5 coupled atmosphere-ocean climate models. Geophysical Research Letters, 39(9), 1-7. https://doi.org/10.1029/2012GL051607

Andrews, T., \& Webb, M. J. (2018). The dependence of global cloud and lapse rate feedbacks on the spatial structure of tropical pacific warming. Journal of Climate, 31(2), 641-654. https://doi.org/10.1175/JCLI-D-17-0087.1

Andrews, T., Gregory, J. M., \& Webb, M. J. (2015). The dependence of radiative forcing and feedback on evolving patterns of surface temperature change in climate models. Journal of Climate, 28(4), 1630-1648. https://doi.org/10.1175/JCLI-D-14-00545.1

Andrews, T., Andrews, M. B., Salcedo, A. B., Jones, G. S., Kulhbrodt, T., Manners, J., ... Tang, Y. (2019). Forcings, feedbacks and climate sensitivity in HadGEM3-GC3.1 and UKESM1, 0-3. https://doi.org/10.1029/2019MS001866

Andrews, T., Gregory, J. M., Paynter, D., Silvers, L. G., Zhou, C., Mauritsen, T., ... Titchner, H. (2018). Accounting for Changing Temperature Patterns Increases Historical Estimates of Climate Sensitivity, 1-10. https://doi.org/10.1029/2018GL078887

Armour, K. C., Bitz, C. M., \& Roe, G. H. (2013). Time-Varying Climate Sensitivity from Regional Feedbacks. Journal of Climate, 26(13), 4518-4534. https://doi.org/10.1175/JCLI-D-12-00544.1

Armour, K. C. (2017). Energy budget constraints on climate sensitivity in light of inconstant climate feedbacks. Nature Climate Change, 7(5), 331-335. https://doi.org/10.1038/nclimate3278

Bader, D. C.; Leung, R.; Taylor, M.; McCoy, R. B. (2019). E3SM-Project E3SM1.0 model output prepared for CMIP6 CMIP. Version 20191230. Earth System Grid Federation. https://doi.org/10.22033/ESGF/CMIP6.2294

Bodas-Salcedo, A., Mulcahy, J. P., Andrews, T., Williams, K. D., Ringer, M. A., Field, P. R., \& Elsaesser, G. S. (2019). Strong dependence of atmospheric feedbacks on mixed-phase microphysics and aerosol-cloud interactions in HadGEM3. Journal of Advances in Modeling Earth Systems, 11, 1735- 1758. https://doi.org/10.1029/2019MS001688

Bony, S., R. Colman, V.M. Kattsov, R.P. Allan, C.S. Bretherton, J.-L. Dufresne, A. Hall, S. Hallegatte, M.M. Holland, W. Ingram, D.A. Randall, D.J. Soden, G. Tselioudis, and M.J. Webb, 2006: How well do we understand and evaluate climate change feedback processes? J. Climate, 19, 3445-3482, doi:10.1175/JCLI3819.1.

Bjordal, J., Storelvmo, T., Alterskjær, K., Carlsen T. (in revision) State-dependent cloud phase feedback makes equilibrium climate sensitivity $>5^{\circ} \mathrm{C}$ plausible. Nature Geoscience

Bloch-Johnson, J., Pierrehumbert, R. T., and Abbot, D. S. (2015), Feedback temperature dependence determines the risk of high warming. Geophys. Res. Lett., 42, 4973-4980. doi: 10.1002/2015GL064240. 
Block, K., and Mauritsen, T. (2013), Forcing and feedback in the MPI-ESM-LR coupled model under abruptly quadrupled $\mathrm{CO}_{2}, J$. Adv. Model. Earth Syst., 5, 676-691, doi:10.1002/jame.20041.

Boucher, O.; Denvil, S.; Caubel, A.; Foujols, M. A. (2018). IPSL IPSL-CM6A-LR model output prepared for CMIP6 CMIP. Version 20191230. Earth System Grid Federation. https://doi.org/10.22033/ESGF/CMIP6.1534

Caballero, R., \& Huber, M. (2013). State-dependent climate sensitivity in past warm climates and its implications for future climate projections. Proceedings of the National Academy of Sciences, 110(35), 14162-14167

Cao, J.; Wang, B. (2019). NUIST NESMv3 model output prepared for CMIP6 CMIP. Version 20191230.Earth System Grid Federation. https://doi.org/10.22033/ESGF/CMIP6.2021

Caldwell, P.M., M.D. Zelinka, K.E. Taylor, and K. Marvel, 2016: Quantifying the Sources of Intermodel Spread in Equilibrium Climate Sensitivity. J. Climate, 29, 513524, https://doi.org/10.1175/JCLI-D-15-0352.1

Caldwell, P.M., M.D. Zelinka, and S.A. Klein, 2018: Evaluating Emergent Constraints on Equilibrium Climate Sensitivity. J. Climate, 31, 39213942, https://doi.org/10.1175/JCLI-D-17-0631.1

Ceppi, P., Brient, F., Zelinka, M. D., \& Hartmann, D. L. (2017). Cloud feedback mechanisms and their representation in global climate models, 8 (August). https://doi.org/10.1002/wcc.403

Ceppi, P., \& Gregory, J. M. (2019). A refined model for the Earth's global energy balance. Climate Dynamics, (May). https://doi.org/10.1007/s00382-019-04825-x

Ceppi, P., \& Gregory, J. M. (2017). Relationship of tropospheric stability to climate sensitivity and Earth's observed radiation budget, 1-6. https://doi.org/10.1073/pnas.1714308114

Danabasoglu, G. (2019). NCAR CESM2-WACCM model output prepared for CMIP6 CMIP piControl. Version 20191230. Earth System Grid Federation. https://doi.org/10.22033/ESGF/CMIP6.10094

Danabasoglu, G.; Lawrence, D.; Lindsay, K.; Lipscomb, W.; Strand, G. (2019). NCAR CESM2 model output prepared for CMIP6 CMIP piControl. Version 20191230.Earth System Grid Federation. https://doi.org/10.22033/ESGF/CMIP6.7733

Dessler, A.E., 2020: Potential Problems Measuring Climate Sensitivity from the Historical Record. J. Climate, 33, 2237-2248, https://doi.org/10.1175/JCLI-D-19-0476.1

Dix, M.; Bi, D.; Dobrohotoff, P.; Fiedle, R. et al. (2019). CSIRO-ARCCSS ACCESS-CM2 model output prepared for CMIP6 CMIP piControl. Version 20200401.Earth System Grid Federation. https://doi.org/10.22033/ESGF/CMIP6.4311

Dong, Y., C. Proistosescu, K.C. Armour, and D.S. Battisti, 2019: Attributing Historical and Future Evolution of Radiative Feedbacks to Regional Warming Patterns using a Green's Function Approach: The Preeminence of the Western Pacific. J. Climate, 32, 54715491, https://doi.org/10.1175/JCLI-D-18-0843.1 
Dufresne, J.-L., and S. Bony, 2008: An assessment of the primary sources of spread of global warming estimates from coupled atmosphere-ocean models. J. Climate, 21, 5135-5144, doi:10.1175/2008JCLI2239.1.

EC-Earth Consortium (EC-Earth) (2019). EC-Earth-Consortium EC-Earth3 model output prepared for CMIP6 CMIP piControl. Version 20191230. Earth System Grid Federation. https://doi.org/10.22033/ESGF/CMIP6.4842

EC-Earth Consortium (EC-Earth) (2019). EC-Earth-Consortium EC-Earth3-Veg model output prepared for CMIP6 CMIP. Version 20191230. Earth System Grid Federation. https://doi.org/10.22033/ESGF/CMIP6.642

Fueglistaler, S. (2019). Observational evidence for two modes of coupling between sea surface temperatures, tropospheric temperature profile, and shortwave cloud radiative effect in the tropics. Geophysical Research

Letters, 46, 9890- 9898. https://doi.org/10.1029/2019GL083990

Forster, P. M., Andrews, T., Good, P., Gregory, J. M., Jackson, L. S., \& Zelinka, M. (2013). Evaluating adjusted forcing and model spread for historical and future scenarios in the CMIP5 generation of climate models, 118, 1139-1150. https://doi.org/10.1002/jgrd.50174

Flato, G., J. Marotzke, B. Abiodun, et al. 2013: Evaluation of Climate Models. In: Climate Change 2013: The Physical Science Basis. Contribution of Working Group I to the Fifth Assess- ment Report of the Intergovernmental Panel on Climate Change [Stocker, T.F., D. Qin, G.-K. Plattner, M. Tignor, S.K. Allen, J. Boschung, A. Nauels, Y. Xia, V. Bex and P.M. Midgley (eds.)]. Cambridge University Press, Cambridge, United Kingdom and New York, NY, USA.

Gettelman, A., Hannay, C., Bacmeister, J. T., Neale, R. B., \& Pendergrass, A. G. (2019). High Climate Sensitivity in the Community Earth System Model Version 2 (CESM2), 2, 83298337. https://doi.org/10.1029/2019GL083978

Golaz, J., Caldwell, P. M., Roekel, L. P. Van, Petersen, M. R., Tang, Q., Wolfe, J. D., ... Williams, D. N. (1850). The DOE E3SM Coupled Model Version 1: Overview and Evaluation at Standard Resolution. https://doi.org/10.1029/2018MS001603

Goosse, H., Kay, J.E., Armour, K.C. et al (2018). Quantifying climate feedbacks in polar regions. Nat Commun 9, 1919 https://doi.org/10.1038/s41467-018-04173-0

Gregory, J. M., Ceppi, T. A. P., \& Webb, T. M. M. J. (2019). How accurately can the climate sensitivity to $\mathrm{CO} 2$ be estimated from historical climate change? Climate Dynamics. https://doi.org/10.1007/s00382-019-04991-y

Gregory, J. M., Ingram, W. J., Palmer, M. A., Jones, G. S., Stott, P. A., Thorpe, R. B., ... Williams, K. D. (2004). A new method for diagnosing radiative forcing and climate sensitivity. Geophysical Research Letters, 31(3), 2-5. https://doi.org/10.1029/2003GL018747

Guo, H.; John, J. G; Blanton, C. et al. (2018). NOAA-GFDL GFDL-CM4 model output. Version 20191230. Earth System Grid Federation. https://doi.org/10.22033/ESGF/CMIP6.1402 


\section{Manuscript submitted to Journal of Climate (currently in revision) ---- This is a non peer-reviewed version on EarthArXiv ----}

Hajima, T.; Abe, M.; Arakawa, O. et al. (2019). MIROC MIROC-ES2L model output prepared for CMIP6 CMIP piControl. Version 20191230.Earth System Grid Federation. https://doi.org/10.22033/ESGF/CMIP6.5710

Huang, Y., Xia, Y., and Tan, X. (2017), On the pattern of $\mathrm{CO}_{2}$ radiative forcing and poleward energy transport, J. Geophys. Res. Atmos., 122, 10,578-10,593, doi:10.1002/2017JD027221.

Kay, J.E., B.R. Hillman, S.A. Klein, et al. 2012: Exposing Global Cloud Biases in the Community Atmosphere Model (CAM) Using Satellite Observations and Their Corresponding Instrument Simulators. J. Climate, 25, 51905207, https://doi.org/10.1175/JCLI-D-11-00469.1)

Krasting, J. P.; John, J. G; Blanton, C.; McHugh, C. et al. (2018). NOAA-GFDL GFDL-ESM4 model output prepared for CMIP6 CMIP piControl. Version 20200401. Earth System Grid Federation. https://doi.org/10.22033/ESGF/CMIP6.8669

Lewis, N., \& Curry, J. (2018). The impact of recent forcing and ocean heat uptake data on estimates of climate sensitivity. Journal of Climate, 31(15), 6051-6071. https://doi.org/10.1175/JCLI-D-17-0667.1

Marvel, K., Schmidt, G., Miller, R. et al. Implications for climate sensitivity from the response to individual forcings. Nature Clim Change 6, 386-389 (2016). https://doi.org/10.1038/nclimate2888

Marvel, K., Pincus, R., Schmidt, G. A., \& Miller, R. L. (2018). Internal variability and disequilibrium confound estimates of climate sensitivity from observations. Geophysical Research Letters, 45, 1595- 1601. https://doi.org/10.1002/2017GL076468

McCoy, D. T., Hartmann, D. L., Zelinka, M. D., Ceppi, P., and Grosvenor, D. P. (2015), Mixedphase cloud physics and Southern Ocean cloud feedback in climate models, J. Geophys. Res. Atmos., 120, 9539- 9554, doi:10.1002/2015JD023603.

Meraner, K., Mauritsen, T., and Voigt, A. (2013), Robust increase in equilibrium climate sensitivity under global warming, Geophys. Res. Lett., 40, 5944- 5948, doi:10.1002/2013GL058118.

NASA Goddard Institute for Space Studies (NASA/GISS) (2018). NASA-GISS GISS-E2.1G model output prepared for CMIP6 CMIP. Version 20191230. Earth System Grid Federation. https://doi.org/10.22033/ESGF/CMIP6.1400

NASA Goddard Institute for Space Studies (NASA/GISS) (2018). NASA-GISS GISS-E2.1H model output prepared for CMIP6 CMIP. Version 20191230. Earth System Grid Federation. https://doi.org/10.22033/ESGF/CMIP6.1421

Park, S.; Shin, J. (2019). SNU SAM0-UNICON model output prepared for CMIP6 CMIP piControl. Version 20191230.Earth System Grid Federation. https://doi.org/10.22033/ESGF/CMIP6.7791

Pincus, R., P. M. Forster, and B. Stevens, 2016: The Radiative Forcing Model Intercomparison Project (RFMIP): Experimental protocol for CMIP6. Geosci. Model Dev., 9, 3447-3460, https://doi.org/10.5194/GMD-9-3447-2016.

Proistosescu, C., \& Huybers, P. J. (2017). Slow climate mode reconciles historical and modelbased estimates of climate sensitivity. Science Advances, 3(7), 1-7. https://doi.org/10.1126/sciadv.1602821 
Ridley, J.; Menary, M.; Kuhlbrodt, T.; Andrews, M.; Andrews, T. (2018). MOHC HadGEM3GC31-LL model output prepared for CMIP6 CMIP. Version 20191230.Earth System Grid Federation. https://doi.org/10.22033/ESGF/CMIP6.419

Rong, X. (2019). CAMS CAMS_CSM1.0 model output prepared for CMIP6 CMIP. Version 20191230. Earth System Grid Federation. https://doi.org/10.22033/ESGF/CMIP6.1399

Rugenstein, M., Bloch-johnson, J., Gregory, J., Mauritsen, T., Li, C., \& Fr, T. L. (2019). Equilibrium climate sensitivity estimated by equilibrating climate models. https://doi.org/10.1029/2019GL083898

Sellar, A. A., Jones, C. G., Mulcahy, J., Tang, Y., Yool, A., Wiltshire, A., ... Zerroukat, M. (2019). UKESM1: Description and evaluation of the UK Earth System Model. https://doi.org/10.1029/2019MS001739

Soden, B. J., \& Held, I. M. (2006). An assessment of Climate Feedbacks in Coupled OceanAtmosphere Models. Journal of Climate, 19, 3354-3360. https://doi.org/10.1175/JCLI3799.1

Seferian, R. (2018). CNRM-CERFACS CNRM-ESM2-1 model output prepared for CMIP6 CMIP. Version 20191230. Earth System Grid Federation. https://doi.org/10.22033/ESGF/CMIP6.1391

Seland, Ø.; Bentsen, M.; Oliviè, D. J. L. et al. (2019). NCC NorESM2-LM model output prepared for CMIP6 CMIP piControl. Version 20191230. Earth System Grid Federation. https://doi.org/10.22033/ESGF/CMIP6.8217

Stevens, B., Sherwood, S. C., Bony, S., \& Webb, M. J. (2016). Prospects for narrowing bounds on Earth's equilibrium climate sensitivity. Earth's Future, 4(11), 512-522. https://doi.org/10.1002/2016EF000376

Storelvmo, T., Tan, I. \& Korolev, A.V. Cloud Phase Changes Induced by $\mathrm{CO}_{2}$ Warming-a Powerful yet Poorly Constrained Cloud-Climate Feedback. Curr Clim Change Rep 1, 288-296 (2015). https://doi.org/10.1007/s40641-015-0026-2

Swart, N. C.; Cole, J. N.S.; Kharin, V. V. et al. (2019). CCCma CanESM5 model output prepared for CMIP6 CMIP historical. Version 20191230. Earth System Grid Federation. https://doi.org/10.22033/ESGF/CMIP6.3610

Tang, Y.; Rumbold, S.; Ellis, R.; Kelley, D. et al. (2019). MOHC UKESM1.0-LL model output prepared for CMIP6 CMIP. Version 20191230. Earth System Grid Federation. https://doi.org/10.22033/ESGF/CMIP6.1569

Tatebe, H.; Watanabe, M. (2018). MIROC MIROC6 model output prepared for CMIP6 CMIP abrupt-4xCO2. Version 20201230. Earth System Grid Federation. https://doi.org/10.22033/ESGF/CMIP6.5411

Tsushima, Y., Emori, S., Ogura, T. et al. Importance of the mixed-phase cloud distribution in the control climate for assessing the response of clouds to carbon dioxide increase: a multimodel study. Clim Dyn 27, 113-126 (2006). https://doi.org/10.1007/s00382-006-0127-7

Volodin, E.; Mortikov, E.; Gritsun, A. et al. (2019). INM INM-CM4-8 model output prepared for CMIP6 CMIP piControl. Version 20191230. Earth System Grid Federation. https://doi.org/10.22033/ESGF/CMIP6.5080 
Voldoire, A. (2018). CNRM-CERFACS CNRM-CM6-1 model output prepared for CMIP6 $C M I P$. Version 20191230. Earth System Grid Federation. https://doi.org/10.22033/ESGF/CMIP6.1375

Webb, M. J., and Coauthors, 2006: On the contribution of local feedback mechanisms to the range of climate sensitivity in two GCM ensembles. Climate Dyn., 27, 17-38, doi:10.1007/s00382-006-0111-2.

Webb, M. J., Lambert, F. H., \& Gregory, J. M. (2013). Origins of differences in climate sensitivity, forcing and feedback in climate models, 677-707. https://doi.org/10.1007/s00382-012-1336-X

Webb MJ, Lock AP, Bretherton CS, et al (2015). The impact of parametrized convection on cloud feedback. Philos Trans A Math Phys Eng Sci. 2015;373(2054):20140414. doi:10.1098/rsta.2014.0414

Wu, T.; Chu, M.; Dong, M. et al. (2018). BCC BCC-CSM2MR model output prepared for CMIP6 CMIP piControl. Version 20191230. Earth System Grid Federation. https://doi.org/10.22033/ESGF/CMIP6.3016

Yukimoto, S.; Koshiro, T.; Kawai, H. et al. (2019). MRI MRI-ESM2.0 model output prepared for CMIP6 CMIP. Version 20191230.Earth System Grid Federation. https://doi.org/10.22033/ESGF/CMIP6.621

Zelinka, M. D., Zhou, C., \& Klein, S. A. (2016). Insights from a refined decomposition of cloud feedbacks, 9259-9269. https://doi.org/10.1002/2016GL069917

Zelinka, M. D., Myers, T. A., McCoy, D., Po-Chedley, S., Caldwell, P. M., Ceppi, P., Klein,

S. A., Taylor, K. E. (2020) Causes of higher climate sensitivity in CMIP6 models. Geophysical Research Letters. doi:10.1029/2019GL085782

Ziehn, T.; Chamberlain, M.; Lenton, A. et al. (2019). CSIRO ACCESS-ESM1.5 model output prepared for CMIP6 CMIP piControl. Version 20200401. Earth System Grid Federation. https://doi.org/10.22033/ESGF/CMIP6.4312

Zhang, J.; Wu, T.; Shi, X. et al. (2018). BCC BCC-ESM1 model output prepared for CMIP6 CMIP piControl. Version 20191230. Earth System Grid Federation. https://doi.org/10.22033/ESGF/CMIP6.3017

Zhou, C., Zelinka, M. D., \& Klein, S. A. (2016). Impact of decadal cloud variations on the Earth's energy budget. Nature Geoscience, 9(12), 871-874. https://doi.org/10.1038/ngeo2828

Zhou, C., Zelinka, M. D., \& Klein, S. A. (2017). Analyzing the dependence of global cloud feedback on the spatial pattern of sea surface temperature change with a Green's function approach. Journal of Advances in Modeling Earth Systems, 9(5), 2174-2189. https://doi.org/10.1002/2017MS001096 


\begin{tabular}{|c|c|c|}
\hline Institution & CMIP6 MODEL & Data Reference \\
\hline CSIRO-ARCCSS & ACCESS-CM2 & Dix et al. 2019 \\
\hline CSIRO & ACCESS-ESM1-5 & Ziehn et al. 2019 \\
\hline $\mathrm{BCC}$ & BCC-CSM2-MR & Wu et al. 2018 \\
\hline $\mathrm{BCC}$ & BCC-ESM1 & Zhang et al. 2018 \\
\hline CAMS & CAMS-CSM1-0 & Rong 2019 \\
\hline CCCma & CanESM5 & Swart et al. 2019 \\
\hline NCAR & CESM2 & Danabasoglu et al. 2019 \\
\hline NCAR & CESM2-WACCM & Danabasoglu 2019 \\
\hline CNRM & CNRM-CM6-1 & Voldoire 2018 \\
\hline CNRM & CNRM-ESM2-1 & Seferian 2018 \\
\hline E3SM-Project & E3SM-1-0 & Bader et al. 2019 \\
\hline EC-Earth-Consortium & EC-Earth3-Veg & EC-Earth 2019 \\
\hline EC-Earth-Consortium & EC-Earth & EC-Earth 2019 \\
\hline NOAA-GFDL & GFDL-CM4 & Guo etal. 2018 \\
\hline NOAA-GFDL & GFDL-ESM4 & Krasting 2018 \\
\hline NASA-GISS & GISS-E2-1-G & NASA/GISS 2018 \\
\hline NASA-GISS & GISS-E2-1-H & NASA/GISS 2018 \\
\hline $\mathrm{MOHC}$ & HadGEM3-GC31-LL & Ridley et al. 2018 \\
\hline INM & INM-CM4-8 & Volodin et al. 2019 \\
\hline $\mathrm{INM}$ & INM-CM5-0 & Volodin et al. 2019 \\
\hline IPSL & IPSL-CM6A-LR & Boucher et al. 2018 \\
\hline MIROC & MIROC-ES2L & Hajima et al. 2019 \\
\hline MIROC & MIROC6 & Tatebe and Watanabe 2018 \\
\hline MRI & MRI-ESM2-0 & Yukimoto et al. 2019 \\
\hline NUIST & NESM3 & Cao and Wang 2019 \\
\hline NCC & NorESM2-LM & Seland et al. 2019 \\
\hline SNU & SAM0-UNICON & Park et al. 2019 \\
\hline $\mathrm{MOHC}$ & UKESM1-0-LL & Tang et al. 2019 \\
\hline
\end{tabular}

Table 1. The CMIP6 models used in this study. 


\begin{tabular}{lccccc}
\hline \multicolumn{1}{c}{ CMIP6 MODEL } & $\boldsymbol{\lambda}_{\mathbf{1 - 2 0}}$ & $\boldsymbol{\lambda}_{\mathbf{2 1}-150}$ & $\Delta \boldsymbol{\lambda}$ & $\mathbf{E C S}_{\mathbf{1 - 2 0}}$ & $\mathbf{E C S}_{\mathbf{2 1 - 1 5 0}}$ \\
\hline ACCESS-CM2 & -1.1 & -0.5 & 0.6 & 3.75 & 5.41 \\
ACCESS-ESM1-5 & -1.14 & -0.42 & 0.73 & 3.07 & 4.93 \\
BCC-CSM2-MR & -1.26 & -0.63 & 0.64 & 2.85 & 3.5 \\
BCC-ESM1 & -1.25 & -0.74 & 0.51 & 2.78 & 3.5 \\
CAMS-CSM1-0 & -1.94 & -1.71 & 0.24 & 2.23 & 2.31 \\
CESM2-WACCM & -1.11 & -0.48 & 0.63 & 3.65 & 5.49 \\
CESM2 & -1.19 & -0.38 & 0.81 & 3.67 & 6.42 \\
CNRM-CM6-1 & -0.92 & -0.81 & 0.1 & 4.29 & 4.76 \\
CNRM-ESM2-1 & -0.49 & -0.58 & -0.09 & 5.7 & 4.91 \\
CanESM5 & -0.69 & -0.62 & 0.08 & 5.44 & 5.75 \\
E3SM-1-0 & -0.77 & -0.47 & 0.3 & 4.78 & 5.77 \\
EC-Earth3-Veg & -1.12 & -0.7 & 0.42 & 3.57 & 4.45 \\
EC-Earth3 & -1.12 & -0.7 & 0.42 & 3.57 & 4.45 \\
GFDL-CM4 & -1.44 & -0.59 & 0.85 & 2.94 & 4.4 \\
GFDL-ESM4 & -1.36 & -1.46 & -0.1 & 2.71 & 2.63 \\
GISS-E2-1-G & -1.46 & -1.2 & 0.26 & 2.74 & 2.87 \\
GISS-E2-1-H & -1.26 & -1.08 & 0.17 & 2.95 & 3.15 \\
HadGEM3-GC31-LL & -0.82 & -0.58 & 0.24 & 4.72 & 5.73 \\
INM-CM4-8 & -1.8 & -0.98 & 0.82 & 1.74 & 1.91 \\
INM-CM5-0 & -1.7 & -1.09 & 0.6 & 1.85 & 2.02 \\
IPSL-CM6A-LR & -1.01 & -0.65 & 0.36 & 3.86 & 4.76 \\
MIROC-ES2L & -1.48 & -1.94 & -0.46 & 2.69 & 2.53 \\
MIROC6 & -1.63 & -1.44 & 0.19 & 2.4 & 2.59 \\
MPI-ESM1-2-HR & -1.51 & -0.81 & 0.7 & 2.77 & 3.34 \\
MRI-ESM2-0 & -1.45 & -0.85 & 0.6 & 2.75 & 3.41 \\
NESM3 & -0.94 & -0.79 & 0.15 & 4.27 & 4.72 \\
NorESM2-LM & -2.06 & -0.83 & 1.23 & 2.24 & 2.98 \\
SAM0-UNICON & -1.16 & -0.74 & 0.42 & 3.6 & 4.19 \\
UKESM1-0-LL & -0.79 & -0.63 & 0.17 & 4.84 & 5.49 \\
\hline Mean & $-1.24(-1.19)$ & $-0.84(-0.74)$ & $0.4(0.42)$ & $3.4(3.07)$ & $4.08(4.4)$ \\
\hline standard deviation & 0.37 & 0.38 & 0.34 & 1.01 & 1.27 \\
\hline
\end{tabular}

Table 2. Estimates of feedback parameter and effective climate sensitivity from abrupt $4 \times \mathrm{CO} 2$ simulations for the CMIP6 GCMs and their multi-model mean. Left to right: feedback parameter over the fast time scale $\left(\lambda_{1-20}\right)$; feedback parameter over the longer time scale $\left(\lambda_{21-150}\right)$; feedback evolution $\left(\Delta \lambda=\lambda_{21-150}-\lambda_{1-20}\right)$; effective climate sensitivity from regressions over years 1-20 $\left(\mathrm{ECS}_{1-20}\right)$; effective climate sensitivity from regressions over years 21-150 $\left(\mathrm{ECS}_{21-150}\right)$. The unit 
for feedback parameters and feedback change is $\mathrm{Wm}^{-2} \mathrm{~K}^{-1}$, for $\mathrm{ECS}_{1-20}$ and $\mathrm{ECS}_{21-150}$ is $\mathrm{K}$. All regressions are calculated using the ordinary least squares regression method.

\begin{tabular}{lccccc}
\hline CMIP5 MODEL & $\boldsymbol{\lambda}_{\mathbf{1 - 2 0}}$ & $\boldsymbol{\lambda}_{\mathbf{2 1 - 1 5 0}}$ & $\boldsymbol{\Delta} \boldsymbol{\lambda}$ & $\mathbf{E C S}_{\mathbf{1 - 2 0}}$ & $\mathbf{E C S}_{\mathbf{2 1 - 1 5 0}}$ \\
\hline ACCESS1-0 & -1.15 & -0.57 & 0.57 & 3.1 & 4.3 \\
ACCESS1-3 & -1.17 & -0.5 & 0.67 & 2.92 & 4.36 \\
bcc-csm1-1 & -1.49 & -0.87 & 0.62 & 2.54 & 3 \\
bcc-csm1-1-m & -1.42 & -0.91 & 0.51 & 2.71 & 3.05 \\
CanESM2 & -1.23 & -0.89 & 0.33 & 3.4 & 3.85 \\
CCSM4 & -1.57 & -0.89 & 0.69 & 2.6 & 3.2 \\
CNRM-CM5 & -1.06 & -1.24 & -0.19 & 3.38 & 3.18 \\
CSIRO-Mk3-6-0 & -1.25 & -0.4 & 0.85 & 2.84 & 5.03 \\
GFDL-CM3 & -1.19 & -0.61 & 0.58 & 3.11 & 4.3 \\
GFDL-ESM2G & -1.51 & -0.64 & 0.87 & 2.32 & 3.02 \\
GFDL-ESM2M & -1.48 & -0.99 & 0.49 & 2.42 & 2.68 \\
GISS-E2-H & -1.86 & -1.4 & 0.46 & 2.21 & 2.39 \\
GISS-E2-R & -2.47 & -1.3 & 1.17 & 1.88 & 2.31 \\
HadGEM2-ES & -0.83 & -0.34 & 0.49 & 4.01 & 6.02 \\
inmcm4 & -1.5 & -1.26 & 0.23 & 2.04 & 2.16 \\
IPSL-CM5A-LR & -0.89 & -0.62 & 0.27 & 3.77 & 4.44 \\
IPSL-CM5A-MR & -0.91 & -0.62 & 0.29 & 3.85 & 4.52 \\
IPSL-CM5B-LR & -1.29 & -0.79 & 0.5 & 2.35 & 2.79 \\
MIROC5 & -1.66 & -1.3 & 0.36 & 2.64 & 2.84 \\
MPI-ESM-LR & -1.38 & -0.87 & 0.51 & 3.32 & 3.89 \\
MPI-ESM-MR & -1.48 & -0.88 & 0.59 & 3.16 & 3.73 \\
MPI-ESM-P & -1.57 & -0.96 & 0.61 & 3.13 & 3.68 \\
MRI-CGCM3 & -1.56 & -1.13 & 0.43 & 2.31 & 2.66 \\
NorESM1-M & -1.61 & -0.77 & 0.85 & 2.34 & 3.18 \\
\hline Mean(Median) & $-1.40(-1.45)$ & $-0.86(-0.88)$ & $0.53(0.51)$ & $2.85(2.78)$ & $3.52(3.19)$ \\
\hline Standard deviation & 0.35 & 0.3 & 0.27 & 0.58 & 0.95 \\
\hline
\end{tabular}

Table 3. Same as Table 2, except for the CMIP5 models. 


\begin{tabular}{|c|c|c|c|}
\hline CMIP6 MODEL & $\mathbf{E C S}_{\text {hist }}$ & $\begin{array}{c}\text { ECS ratio } \\
\text { yrs 21-150 (yrs 1-150) }\end{array}$ & $\begin{array}{c}\lambda^{\prime} \\
\text { yrs 21-150 (yrs1-150) }\end{array}$ \\
\hline ACCESS-CM2 & 4.05 & $1.28(1.13)$ & $0.22(0.12)$ \\
\hline ACCESS-ESM1-5 & 3.13 & $1.41(1.19)$ & $0.31(0.17)$ \\
\hline BCC-CSM2-MR & 2.81 & $1.06(1.04)$ & $0.06(0.05)$ \\
\hline BCC-ESM1 & 3.05 & $1.07(1.05)$ & $0.07(0.05)$ \\
\hline CAMS-CSM1-0 & 2.19 & $0.98(1.02)$ & $-0.04(0.03)$ \\
\hline CESM2 & 4.16 & $1.4(1.21)$ & $0.32(0.2)$ \\
\hline CESM2-WACCM & 3.9 & $1.32(1.17)$ & $0.25(0.15)$ \\
\hline CNRM-CM6-1 & 4.72 & $0.96(1.02)$ & $-0.03(0.02)$ \\
\hline CNRM-ESM2-1 & 4.52 & $0.91(1.02)$ & $-0.06(0.01)$ \\
\hline CanESM5 & 5.33 & $1.05(1.04)$ & $0.03(0.03)$ \\
\hline E3SM-1-0 & 4.91 & $1.1(1.07)$ & $0.06(0.04)$ \\
\hline EC-Earth3 & 3.87 & $1.09(1.1)$ & $0.08(0.09)$ \\
\hline EC-Earth3-Veg & 3.91 & $1.08(1.09)$ & $0.07(0.08)$ \\
\hline GFDL-CM4 & 3.16 & $1.12(1.14)$ & $0.13(0.16)$ \\
\hline GFDL-ESM4 & 2.55 & $0.88(0.98)$ & $-0.2(-0.02)$ \\
\hline GISS-E2-1-G & 2.57 & $1(1.03)$ & $0(0.04)$ \\
\hline GISS-E2-1-H & 2.95 & $0.99(1.02)$ & $-0.01(0.03)$ \\
\hline HadGEM3-GC31-LL & 5.24 & $1.08(1.05)$ & $0.06(0.04)$ \\
\hline INM-CM4-8 & 1.74 & $1.05(1.04)$ & $0.09(0.07)$ \\
\hline INM-CM5-0 & 1.84 & $1(1.02)$ & $0(0.04)$ \\
\hline IPSL-CM6A-LR & 4.31 & $1.01(1.02)$ & $0.01(0.02)$ \\
\hline MIROC-ES2L & 2.62 & $0.88(1.02)$ & $-0.23(-0.04)$ \\
\hline MIROC6 & 2.37 & $0.95(1.03)$ & $-0.09(0.05)$ \\
\hline MPI-ESM1-2-HR & 2.63 & $1.18(1.11)$ & $0.23(0.15)$ \\
\hline MRI-ESM2-0 & 2.68 & $1.09(1.11)$ & $0.11(0.13)$ \\
\hline NESM3 & 4.78 & $0.91(0.96)$ & $-0.08(-0.04)$ \\
\hline NorESM2-LM & 1.88 & $1.1(1.16)$ & $0.22(0.34)$ \\
\hline SAM0-UNICON & 3.38 & $1.05(1.06)$ & $0.06(0.06)$ \\
\hline UKESM1-0-LL & 5.12 & $1.06(1.04)$ & $0.05(0.03)$ \\
\hline CMIP6 Mean & 3.46 & $1.07(1.07)$ & $0.06(0.07)$ \\
\hline CMIP6 std & 1.08 & $0.13(0.06)$ & $0.13(0.08)$ \\
\hline CMIP5 Mean & 2.807 & $1.095(1.073)$ & $0.092(0.086)$ \\
\hline CMIP5 std & 0.59 & $0.134(0.063)$ & $0.141(0.069)$ \\
\hline
\end{tabular}

Table 4. Estimates of ECS ${ }_{\text {hist }}$ ECS-to-ECS ${ }_{\text {hist }}$ ratio and $\lambda^{\prime}$ (the change in feedback from historical period to equilibrium) for individual CMIP6 models and ensemble-means of CMIP5 and CMIP6, to be compared with Table S2 in Lewis and Curry (2018). For ECS-to-ECS hist $_{\text {ratio and }} \lambda^{\prime}$, the results shown are calculated with the values of effective ECS derived from regressions over years 21-150 (or years 1-150), using the Deming regression method. 

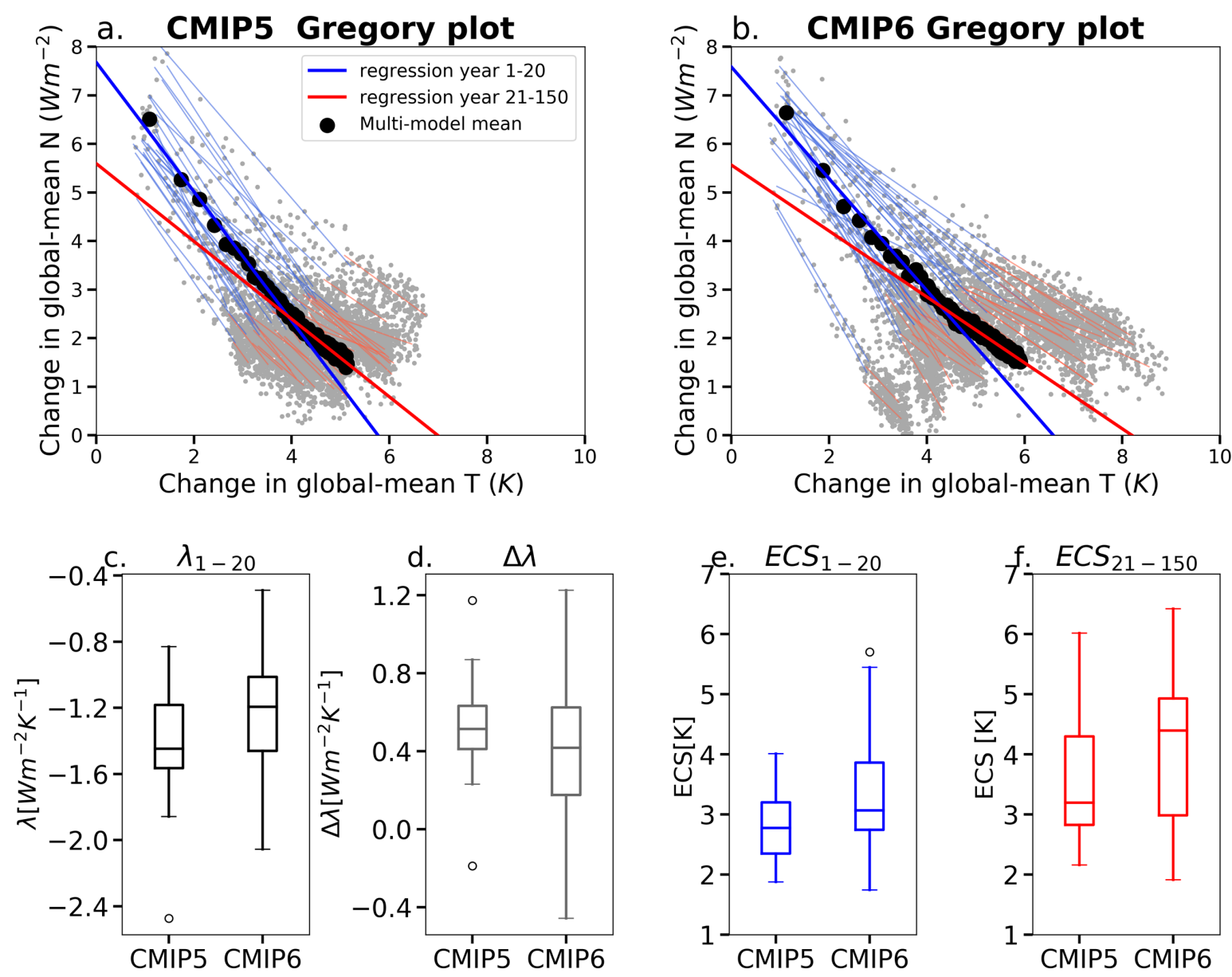

Figure 1. (a, b) Gregory plots for (a) CMIP5 and (b) CMIP6: annual-mean change in global-mean net TOA radiation $\left(\mathrm{Wm}^{-2}\right)$ against annual-mean change in global-mean surface air temperature $(\mathrm{K})$ from abrupt $4 \mathrm{xCO}_{2}$ experiments. Gray dots denote each year from each model, black dots denote each year of multi-model means. Thin (thick) lines show regression fits for years 1-20 (blue) and for years 21-150 (red) for each model (multi-model means). The slope of blue lines represents feedback parameter on the fast time-scale $\left(\lambda_{1-20}\right)$, and the slope of red lines represents feedback parameter on the longer time-scale $\left(\lambda_{21-150}\right)$. (c, $\mathrm{d}$, e, f) Box plots of $\lambda_{1-20}\left(\mathrm{Wm}^{-2} \mathrm{~K}^{-1}\right), \Delta \lambda\left(\mathrm{Wm}^{-2} \mathrm{~K}^{-}\right.$ $\left.{ }^{1}\right), \mathrm{ECS}_{1-20}(\mathrm{~K})$ and $\mathrm{ECS}_{21-150}(\mathrm{~K})$ in CMIP5 (left) and CMIP6 (right) models. 


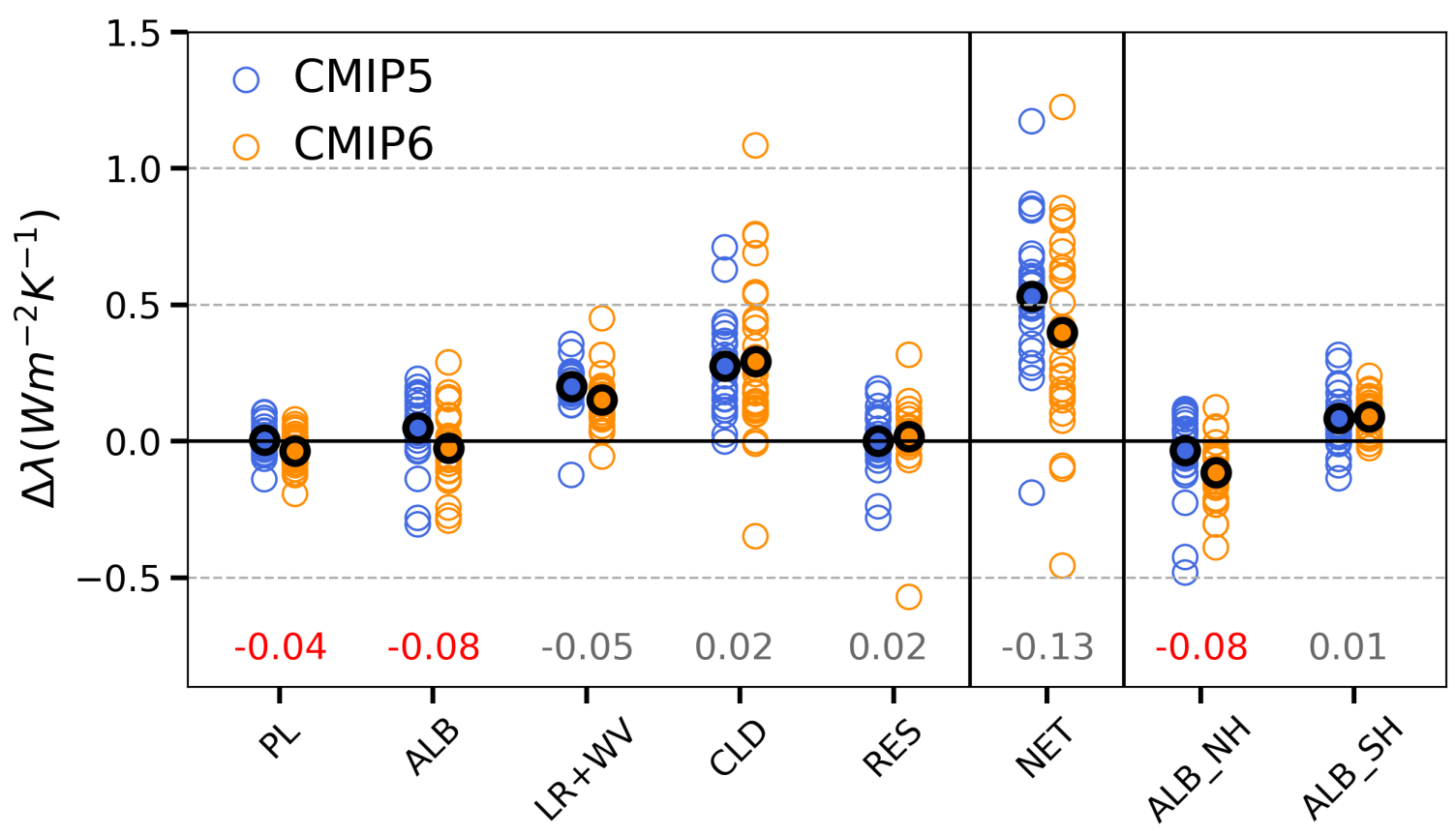

Figure 2. $\Delta \lambda$ for each individual CMIP5 models (blue circles), CMIP6 models (orange circles), and their multi-model means (black circles), decomposed into contributions of (from left to right) Planck (PL), surface-albedo (ALB), the sum of lapse-rate (LR) and water vapor (WV), net cloud (CLD), and residual (RES), respectively. The $\Delta \lambda_{\mathrm{ALB}}$ is further broken down into contributions from Northern Hemisphere (ALB_NH) and Southern Hemisphere (ALB_SH). The differences between CMIP5-means and CMIP6-means are printed at the bottom, with red numbers highlighting multi-model means that are significantly different $(\mathrm{p}<0.05)$. 


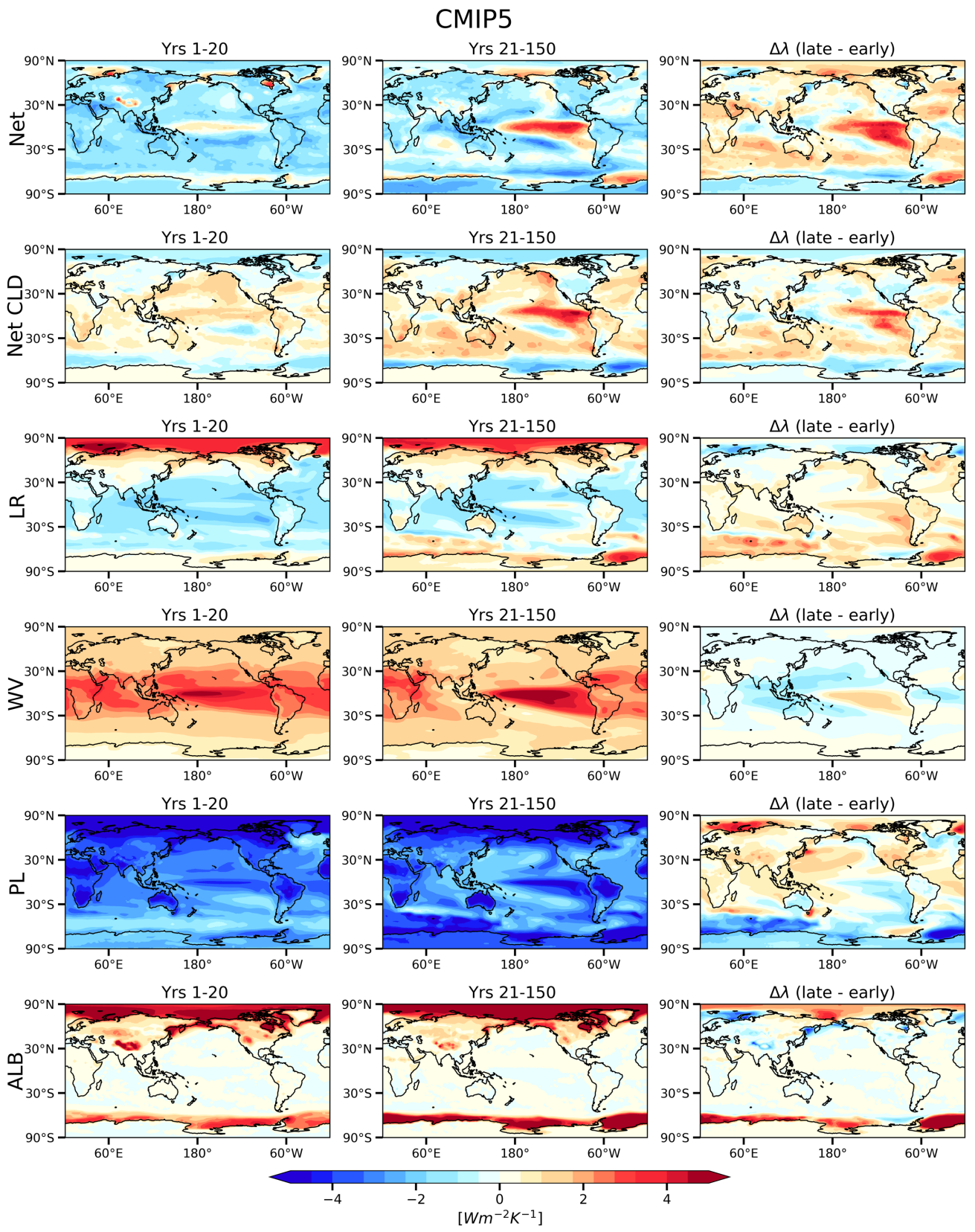

Figure 3. CMIP5 ensemble-mean spatial patterns of the local radiative feedback components (calculated by regressing the local $N$ against global-mean $T$ ). (top to bottom) net feedback, net cloud feedback, lapse-rate feedback, water-vapor feedback, Planck feedback, surface-albedo feedback, on (left) years 1-20 and (middle) years 21-150 time-scales, and (right) the change (late minus early). 
(a) CMIP6
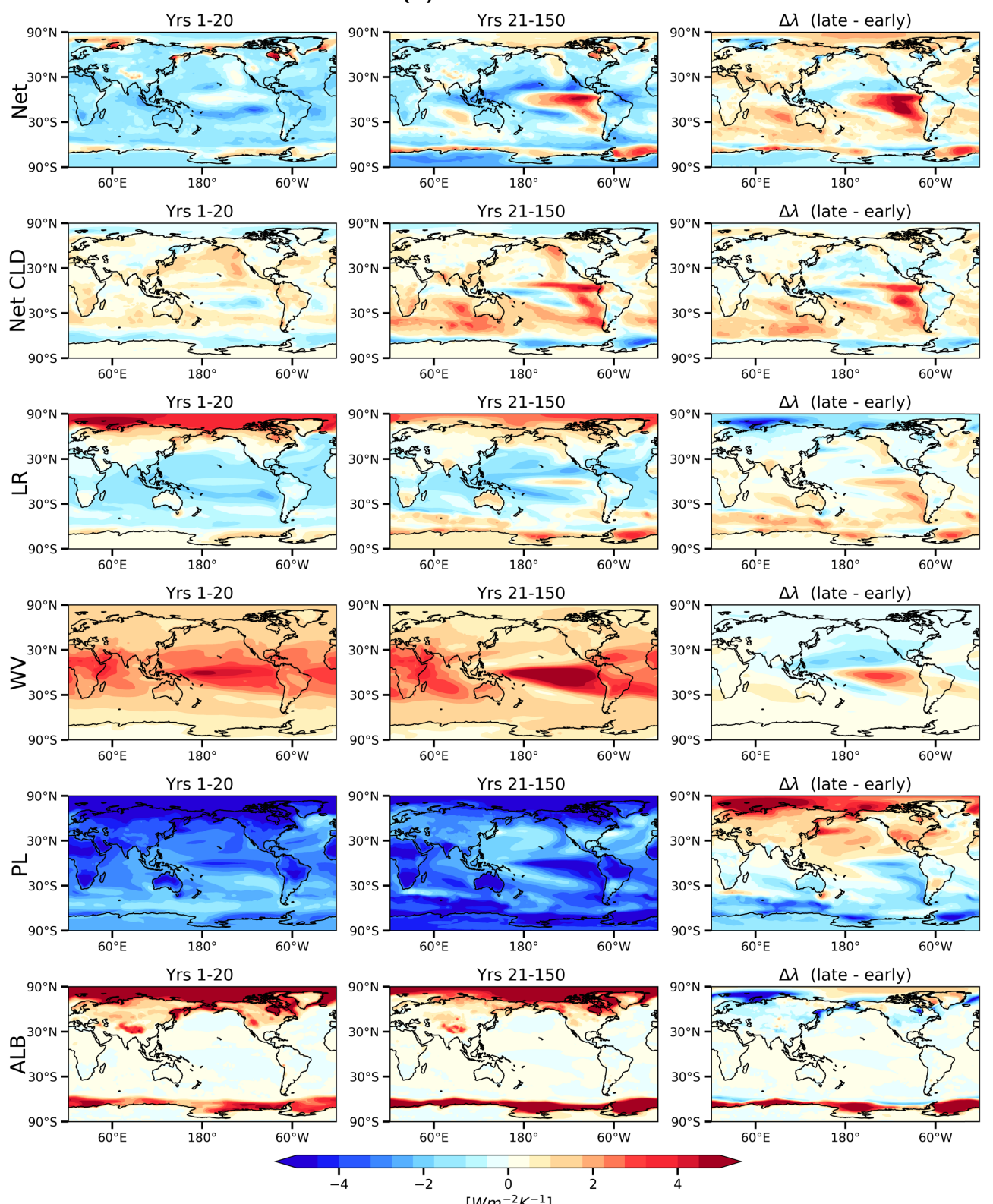

(b) Difference (CMIP6 - CMIP5)

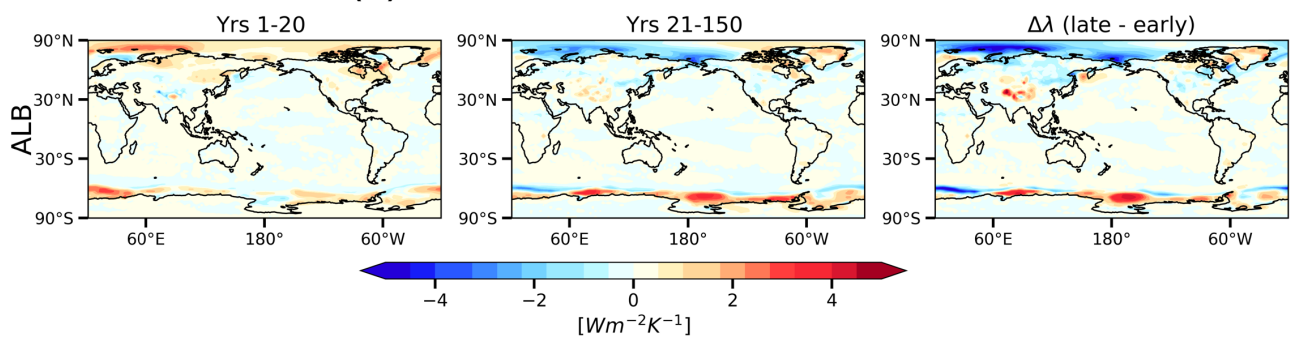

Figure 4. (a) same as Fig. 3, except for CMIP6 ensemble means. (b) the difference in ensemblemean surface-albedo feedback between CMIP5 and CMIP6 (CMIP6 minus CMIP5). 


\section{CMIP5}

(a).

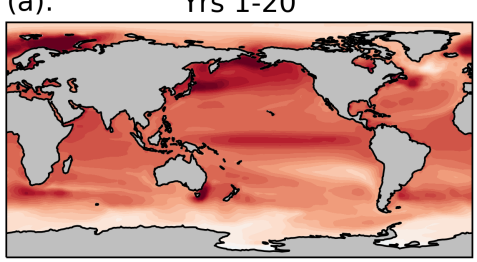

(d).

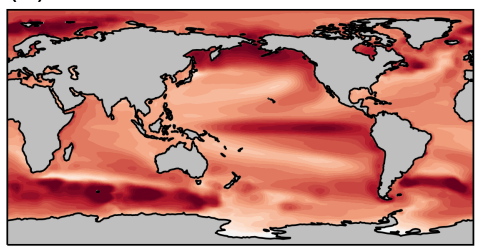

(g). Change (late - early)

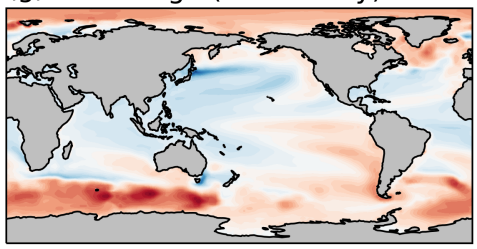

CMIP6

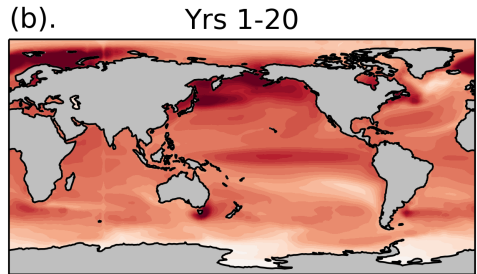

(e).

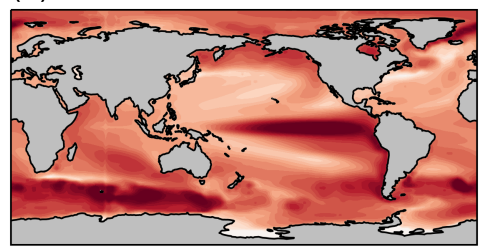

(h). Change (late - early)

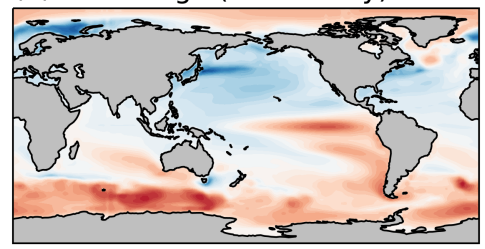

Difference(6-5)
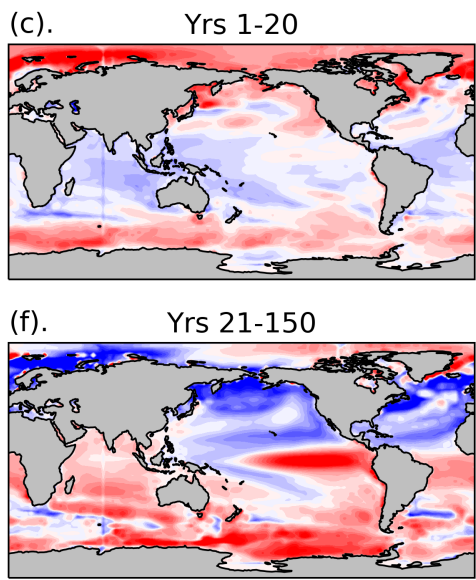

(i). Change (late - early)
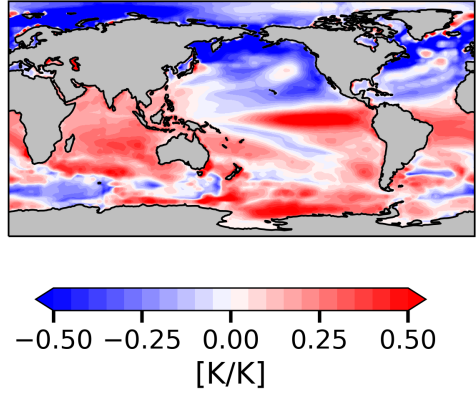

Figure 5. Spatial patterns of SST changes (SST*) over (top to bottom) years 1-20, years 21-150, and their changes (late minus early), for (left) CMIP5 multi-model mean, (middle) CMIP6 multimodel mean, and (right) the difference (CMIP6 minus CMIP5). The values of SST* are calculated as the regression slope of local SST changes against global-mean SST changes, such that the global mean of panels $(a, b, d, e)$ is one by construction. Note that the color scales in the left two columns and in the right column are different. 


\section{CMIP5 reconstruction}
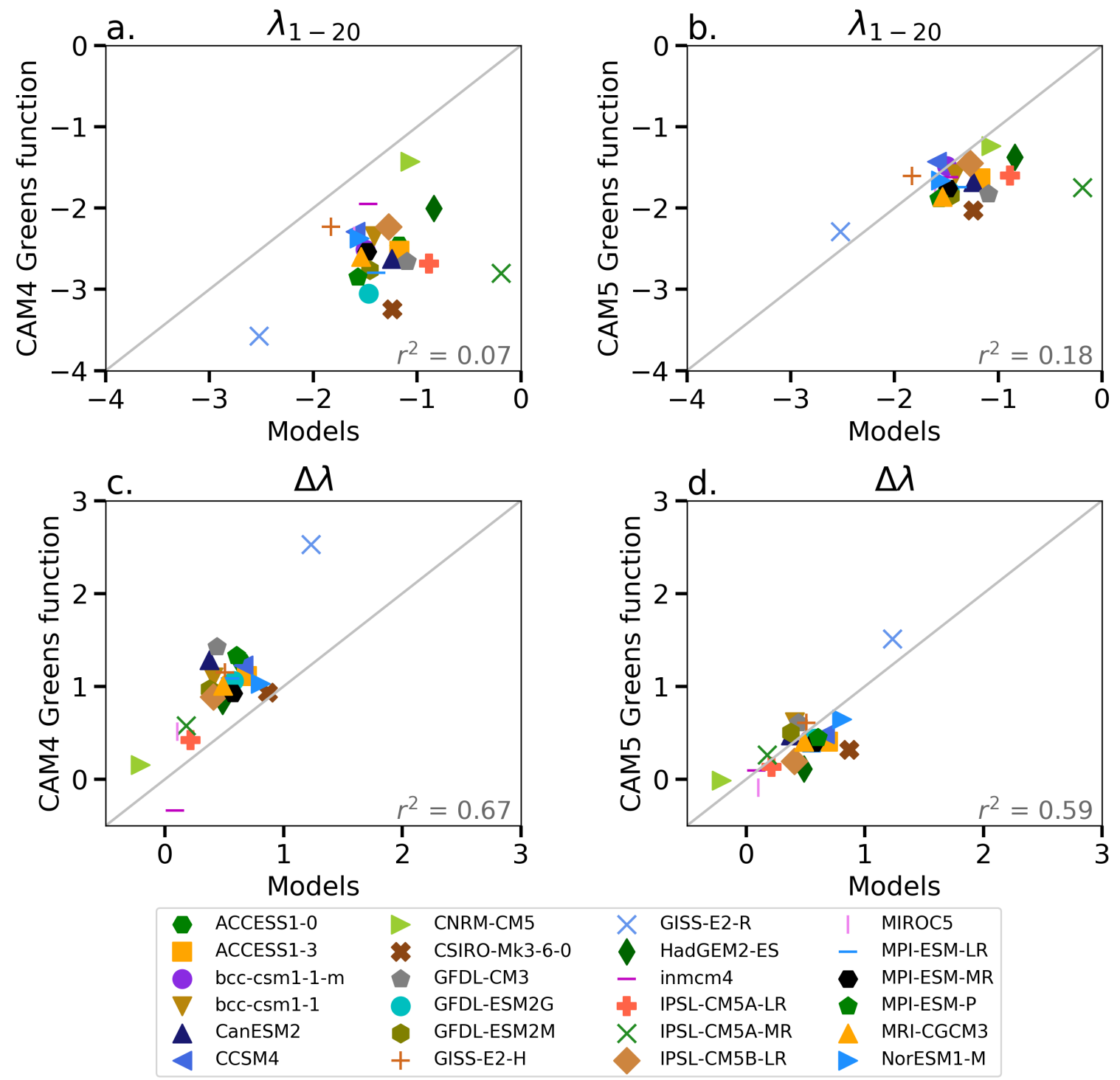

Figure 6. Comparison of (top) $\lambda_{1-20}$ and (bottom) $\Delta \lambda$ from CMIP5 models and those from (left) CAM4 Green's function, (right) CAM5 Green's function, respectively. Gray lines are $\mathrm{y}=\mathrm{x}$ reference line. Correlation coefficient is printed in each panel. 

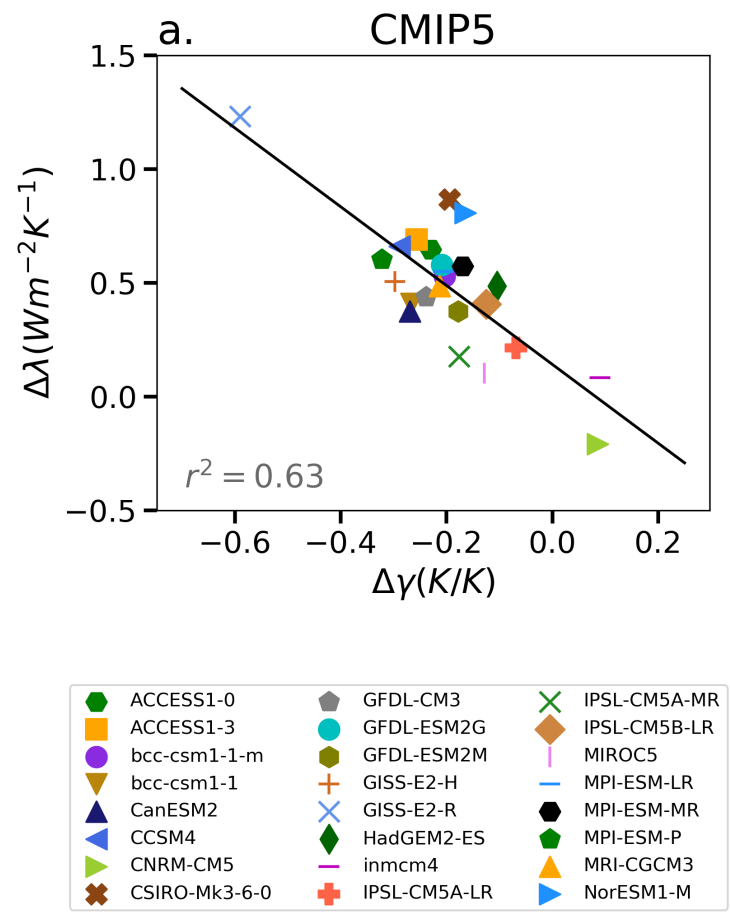

b.

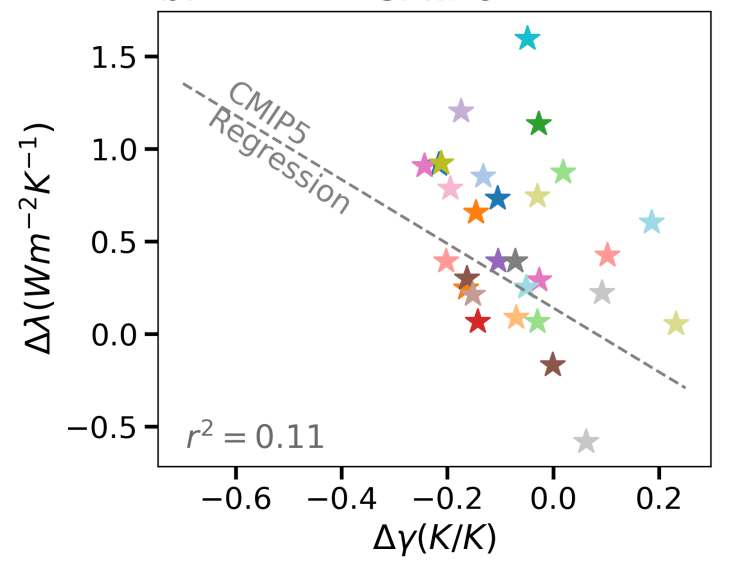

Figure 7. The relation between the change in net feedback $(\Delta \lambda)$ and the change in the proposed West Pacific warm-pool warming ratio $(\Delta \gamma)$, for (left) CMIP5 models and (right) CMIP6 models. The linear fit for CMIP5 models is plotted as the black line in the left panel, and the grey dashed line in the right panel. 

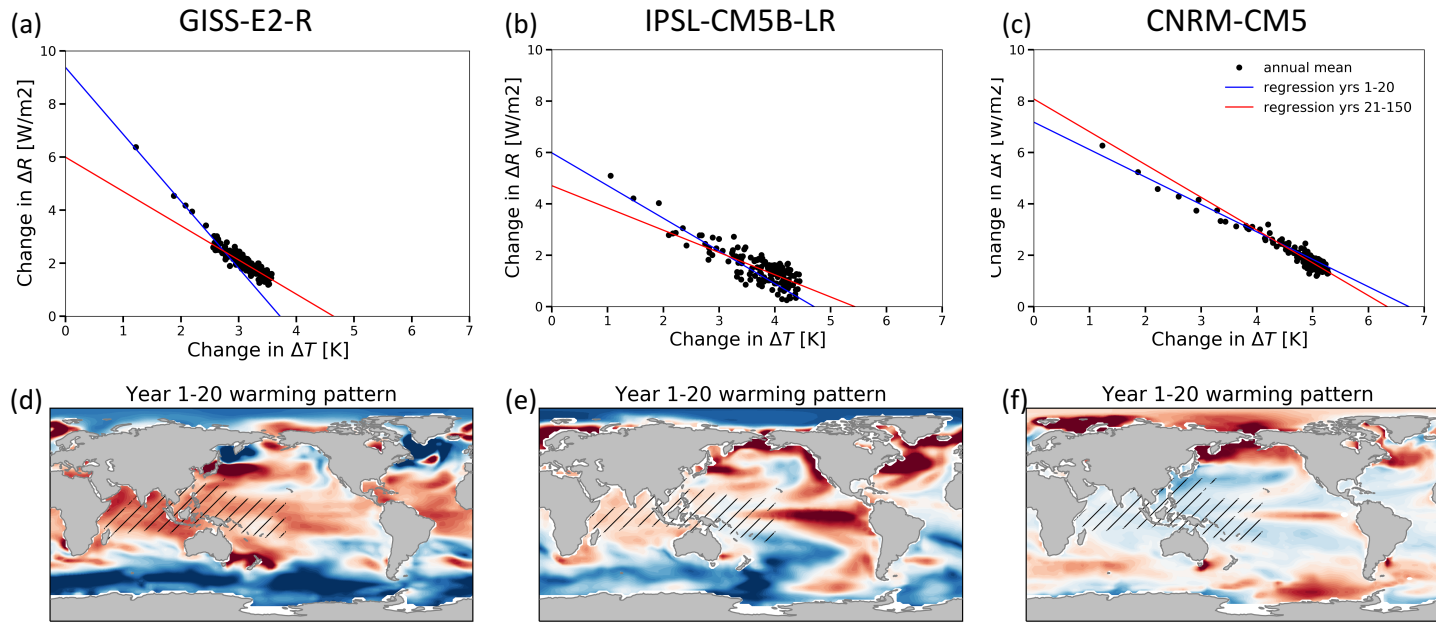

(g)

Year 21-150 warming pattern
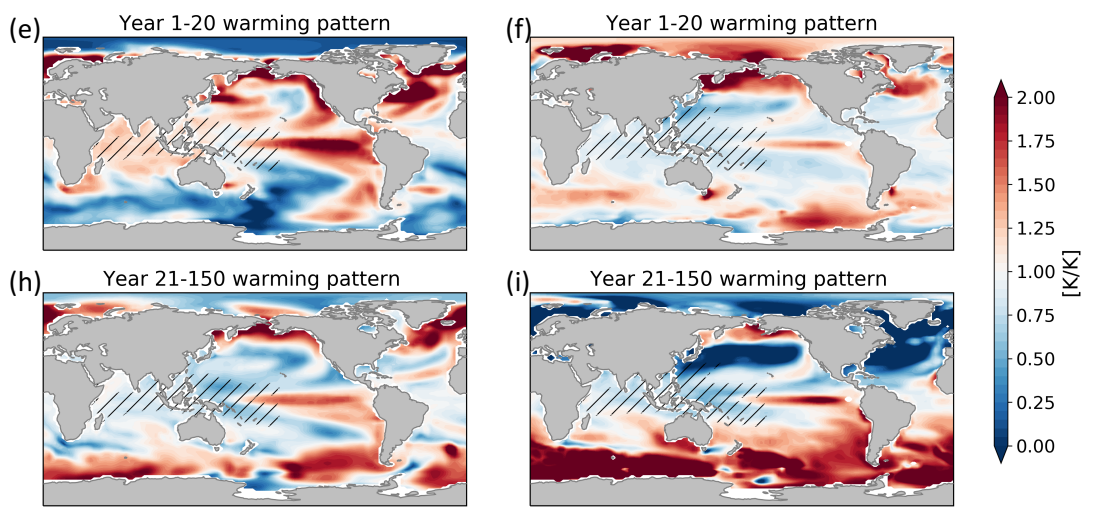

(j)

Change in warming pattern
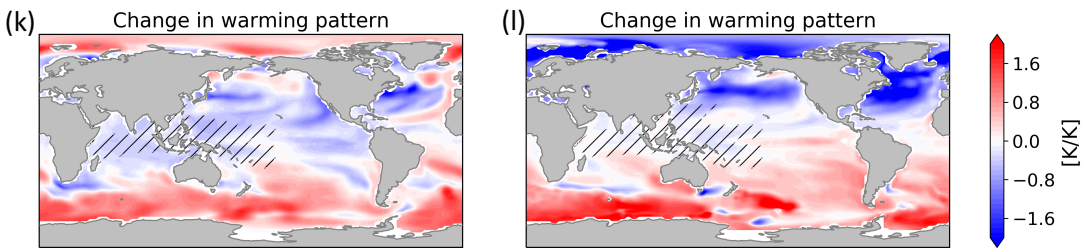

Figure 8. Gregory plots (top) and patterns of SST changes (bottom three rows) for (left) GISS-E2$\mathrm{R}$, (middle) IPSL-CM5B-LR, and (right) CNRM-CM5. $(\mathrm{a}-\mathrm{c})$ Colored lines show regression fits for years 1-20 (blue) and for years 21-150 (red). (d - i) plots show the regression slope of local SST changes against global-mean SST changes over $(d-f)$ years 1-20, $(g-i)$ years $21-150$, and $(j-$ i) their differences (later minus early). The hatchings highlight the warm-pool ascent regions in each model. 


\section{CMIP5}

(a)

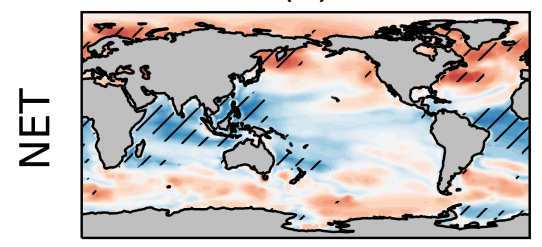

(c)

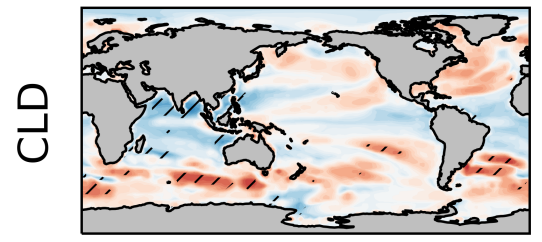

(e)

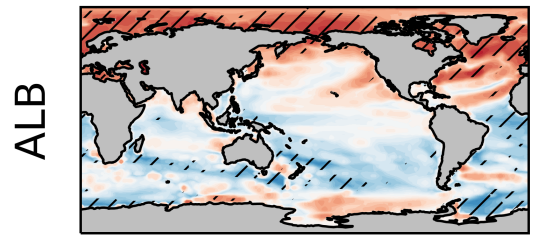

(g)

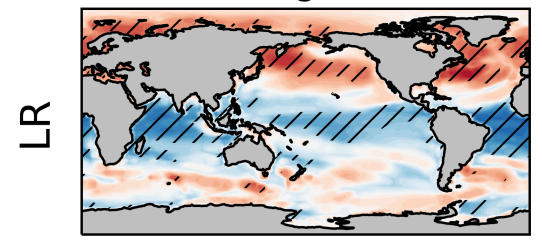

(i)

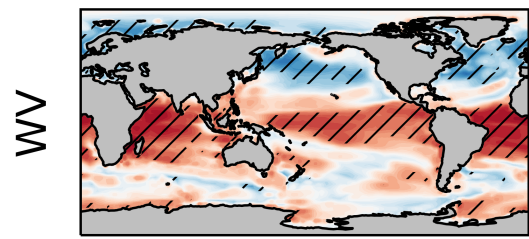

CMIP6

(b)

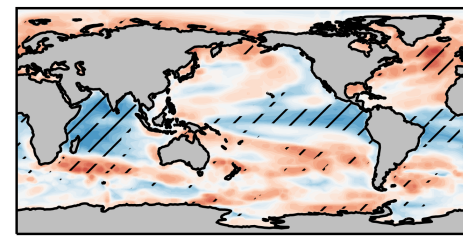

(d)

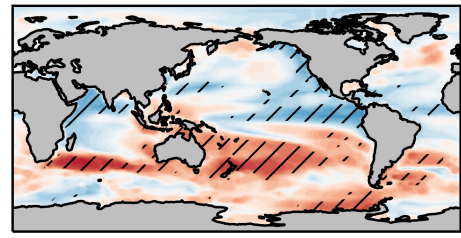

(f)

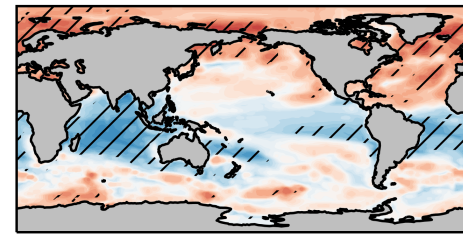

(h)

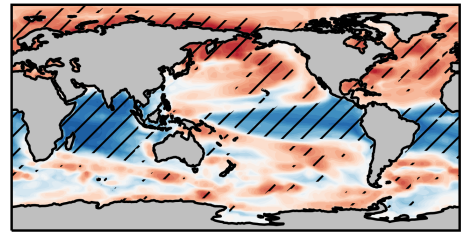

(j)
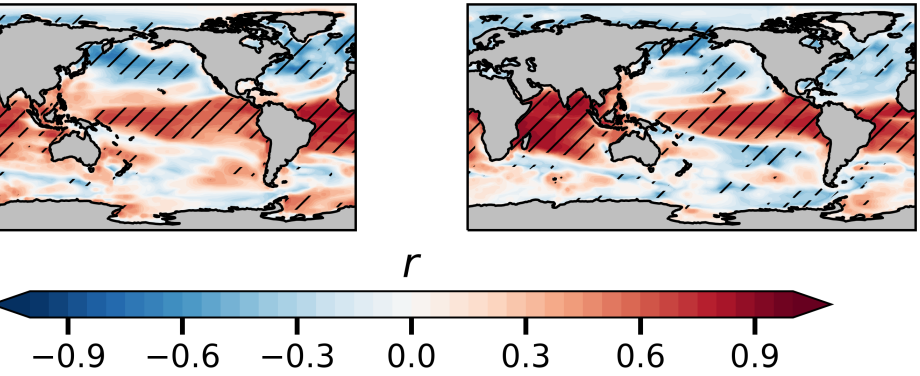

Figure 9. Correlation coefficients $(r)$ for local regression of global-mean $\Delta \lambda$ against local $\Delta \mathrm{SST}^{*}$ (local SST warming rate relative to global-mean SST change) across (left) CMIP5 models and (right) CMIP6 models. Top to bottom: net $\Delta \lambda$, cloud $\Delta \lambda$, surface-albedo $\Delta \lambda$, lapse rate $\Delta \lambda$, and water vapor feedback. Hatchings mark grids where correlations are significant (i.e. $\mathrm{p}<0.05$ ). 